PASOLD, Cesar Luiz. El Taedium Vitae De Norberto Bobbio Y La Ética Médica. Revista Eletrônica Direito e Política, Programa de Pós-Graduação Stricto Sensu em Ciência Jurídica da UNIVALI, Itajaí, v.11, n.1, $1^{0}$ quadrimestre de 2016. Disponível em: www.univali.br/direitoepolitica - ISSN 1980-7791.

\title{
EL TAEDIUM VITAE DE NORBERTO BOBBIO Y LA ÉTICA MÉDICA $^{1}$
}

\section{THE TAEDIUM VITAE OF NORBERTO BOBBIO AND THE MEDICAL}

\author{
ETHICS
}

Cesar Luiz Pasold²

SUMÁRIO: Introducción; 1. La Muerte y la síntesis de la Vida Profesional de Bobbio; 2. El Taedium Vitae de Norberto Bobbio y la ética de la decisión de su hijo, el médico Marco Bobbio; Consideraciones Finales. Referencias

\section{RESUMEN}

En los últimos meses de su vida Norberto Bobbio, por entonces viudo hacía 3 años, limitado físicamente, deprimido y solitario, a menudo repetía a los familiares la expresión latina Taedium Vitae, indicando su cansancio de la vida. Al final de 2003, a los 94 años que había cumplido en octubre, fue atacado por una neumonía y sometido a una internación hospitalaria en virtud de su dificultad para respirar, pero luego mejoró y retornó a su hogar. El 7 de enero de 2004 su estado se agravó mucho, y por decisión de su hijo Marco Bobbio, médico cardiólogo, fue deliberadamente dispensado cualquier tratamiento para el prolongamiento de su vida o para abreviar la llegada de su muerte, que ocurrió el 9 de enero de 2004. En el presente artículo se presenta un relato, resumido en ciertos momentos, pero siempre detallado cuando se trata del retrato de la riqueza intelectual que comprueba la fructífera vida intelectual y científica de Norberto Bobbio, cultivando su memoria cuando pasaron ya once años de su fallecimiento. A seguir se abordan aspectos destacados de la Ética en general y de cinco Códigos de Ética en lo que concierne al caso concreto de la decisión de su hijo médico. En las Consideraciones Finales hay una síntesis y estímulos a la continuidad de estudios y reflexión sobre el tema, siempre desde el punto de vista del respeto a la Vida, a la Muerte y a la Dignidad Humana.

\footnotetext{
${ }^{1}$ Versão para o espanhol realizada pelo NELLE-UNIVALI-Brasil.

2 Doctor en Derecho del Estado por la USP; Posdoctor en Derecho de las Relaciones Sociales por la UFPR; Profesor y Orientador de Disertaciones y Tesis en los Cursos de Maestría y de Doctorado en Ciencia Jurídica de la Universidad del Vale do Itajaí - UNIVALI. Abogado- OAB/SC 943. CV Lattes: http://lattes.cnpq.br/6851573982650146

Email: cesarpasold@gmail.com
} 
PASOLD, Cesar Luiz. El Taedium Vitae De Norberto Bobbio Y La Ética Médica. Revista Eletrônica Direito e Política, Programa de Pós-Graduação Stricto Sensu em Ciência Jurídica da UNIVALI, Itajaí, v.11, n.1, $1^{0}$ quadrimestre de 2016. Disponível em: www.univali.br/direitoepolitica - ISSN 1980-7791.

Palabras clave: Taedium Vitae; Dignidad Humana; Ética Médica.

\section{ABSTRACT}

In the last months of his life Norberto Bobbio, by then widowed three years ago, physically limited, depressed and lonely, often repeated to the Latin family Taedium Vitae, indicating their weariness of life. At the end of 2003, at age 94 he had met in October, he was attacked by pneumonia and undergone hospitalization because of its difficulty breathing, but then improved and returned home. On January 7, 2004 his condition much worse, and the decision of his son Marco Bobbio, cardiologist, was deliberately dispensed any treatment for the prolongation of life or to shorten the arrival of his death, which occurred on January 9 2004. A story, summarized at times, but always detail when it comes Portrait of intellectual wealth that checks the fruitful intellectual and scientific life of Norberto Bobbio, cultivating their memory when they spent eleven years of presented in this article death. A follow highlights of the Ethics in general and five Codes of Ethics with respect to the case of the decision to your doctor son addressed. In the conclusion there is a synthesis and encouragement to continue their studies and reflection on the subject, always from the point of view of respect for life, death and human dignity.

KEYWORDS: Taedium Vitae; Human dignity; Medical Ethics.

\section{INTRODUCCIÓN}

El Objeto de este artículo es la percepción de la circunstancia de la muerte de una persona, en este caso concreto Norberto Bobbio, desde la perspectiva de su fructífera vida y obra, y de aspectos de Ética General y de Ética Médica.

El Objetivo de este artículo es, en un primera etapa, relatar en algunos momentos detalladamente $\mathrm{y}$ en otros resumidamente, la fructífera vida intelectual, científica y pública de Norberto Bobbio. A continuación, examinar desde el punto de vista de la Ética General y de la Ética Médica las circunstancias de la muerte de Bobbio, y especialmente en la pre muerte, considerada la decisión de su hijo, el médico cardiólogo Marco Bobbio, de no someterlo a tratamientos meramente prolongadores de la vida. La línea de análisis aquí adoptada es la de que no se intenta encuadrar o no a Marco Bobbio sino, objetivamente, verificar la situación frente a ciertas normas éticas, seleccionadas a título ejemplificativo. 
PASOLD, Cesar Luiz. El Taedium Vitae De Norberto Bobbio Y La Ética Médica. Revista Eletrônica Direito e Política, Programa de Pós-Graduação Stricto Sensu em Ciência Jurídica da UNIVALI, Itajaí, v.11, n.1, $1^{0}$ quadrimestre de 2016. Disponível em: www.univali.br/direitoepolitica - ISSN 1980-7791.

En las Consideraciones Finales se resume objetivamente lo expuesto y se estimula al Lector a la reflexión e investigación continuadas del tema, desde el marco referencial del respeto a la Vida, a la Muerte y a la Dignidad Humana.

En la fase de investigación fue utilizado el Método Inductivo, en el tratamiento de los datos el Método Histórico y el Método Analítico, y el informe de la investigación en la forma del presente artículo se fundamentó en la Base Lógica Inductiva ${ }^{3}$. Las técnicas de apoyo empleadas fueron la Técnica de la Categoría, del Referente y de la Investigación Bibliográfica ${ }^{4}$

El presupuesto estratégico del presente Artículo es la adopción de conceptos operacionales muy específicos y diferenciados entre las categorías Ética, Moral y Derecho, tema que se trata a seguir en la presente Introducción. Aquí el Autor del presente artículo mantiene una postura conceptual construida y consolidada a lo largo de siete años, especialmente en tres momentos/obras intituladas "O Advogado e a Advocacia"" (2001), "Personalidade e Comunicação" (2005) y el "Ensaio sobre a Ética de Norberto Bobbio"7 (2008), y resultantes de reflexiones a partir de lecturas atentas de un conjunto de obras muy importantes para tales concepciones ${ }^{8}$.

\footnotetext{
${ }^{3}$ Importante alertar que no fue utilizado el método comparativo en ninguna de las fases de la Investigación cuyos resultados son relatados en este artículo. Esta reserva es relevante porque lo que se hizo fue ilustrar el examen del caso concreto - actuación del médico Marco Bobbio en la situación terminal de Norberto Bobbio, sin desconsiderar la relación de padre e hijo verificando la normativa en cinco Códigos Deontológicos o Éticos Médicos seleccionados, entre los cuales, con énfasis, el de Brasil.
}

4 CESAR LUIZ PASOLD, Metodologia da Pesquisa Jurídica: teoria e prática, 13a edición, Florianópolis, Conceito Editorial, 20155, p. 97 a 111, p.27 a 66, 215, siguiendo este orden.

${ }^{5}$ CESAR LUIZ PASOLD, $\mathbf{O}$ advogado e a advocacia, 3a edición, Florianópolis, OAB/SC Editora, 2001.

${ }^{6}$ CESAR LUIZ PASOLD, Personalidade e Comunicação, 2a edición, Florianópolis, Plus Saber Editora, 2005.

7 CESAR LUIZ PASOLD, Ensaio sobre a Ética de Norberto Bobbio, Florianópolis, Conceito Editorial, 2008. En especial de p.24 a 29.

${ }^{8}$ Es justo homenajear aquí a estos autores y obras que tanto dieron y continúan dando soporte a la fundamentación y sustentación de los Conceptos Operacionales entonces construidos y hasta aquí empleados con convicción teórica y práctica, pero siempre desde la perspectiva de los impactos y cambios que puedan venir, a percibir con la humildad científica que el autor del 
PASOLD, Cesar Luiz. El Taedium Vitae De Norberto Bobbio Y La Ética Médica. Revista Eletrônica Direito e Política, Programa de Pós-Graduação Stricto Sensu em Ciência Jurídica da UNIVALI, Itajaí, v.11, n.1, $1^{0}$ quadrimestre de 2016. Disponível em: www.univali.br/direitoepolitica - ISSN 1980-7791.

Se registra en el presente artículo como propuesta epistemológica operacional una matriz conceptual específica de las categorías Ética y Moral, entendidas como inconfundibles entre sí, y así también para la categoría del Derecho. La Moral es considerada una disposición subjetiva de determinación de lo que es correcto y de lo que es incorrecto para establecer, a partir de tal presupuesto, una noción propia del Bien y del Mal. Por su parte, la Ética es propuesta como la atribución [también subjetiva] de valor o importancia a personas, condiciones y comportamientos, y en tal dimensión es establecida una noción específica de Bien a ser alcanzado en determinadas realidades concretas, las institucionales y/o las históricas ${ }^{9}$. El concepto operacional para la categoría Derecho aquí propuesto para efectos de raciocinio es el que lo entiende como

presente artículo procura siempre cultivar y practicar. Esta bibliografía de lectura referencial fue: NICOLA ABBAGNANO, Dicionário de Filosofia, Traducción de Alfredo Bosi, São Paulo: Martins Fontes, 1998. Título original: Dizionario di Filosofia; ARISTOTELES, Ética a Nicômacos, Traducción de Mário da Gama Kury, 3a edición, Brasília, Editora Universidade de Brasília,1999. Título original: Ethicon Nikomacheion; ARISTÓTELES, Arte Retórica e Arte Poética, Traducción de Antonio Pinto de Carvalho, Rio de Janeiro, Tecnoprint, s/d, Título original: Art Rhétorique et Art Poétique; FÁBIO KONDER COMPARATO, Ética- Direito, Moral e Religião no Mundo Moderno, $3^{3}$ reimpresión, São Paulo, Companhia das Letras, 2006; M. S. FIGUEIRA, "A eticidade no ofício de julgar" Em: Verbis. (12), 1998; JOSÉ ARTHUR GIANOTTI, "Moralidade Pública e Moralidade Privada" En NOVAES, Adauto (org.), Ética, São Paulo, Companhia das Letras/Secretaria Municipal de Cultura, 1992, p.239 a 245; G. W. F. HEGEL, Princípios da filosofia do direito, Traducción de Orlando Vitorino, São Paulo, Martins Fontes, 1997; WILHELMUS GODEFRIDUS HERMANS, Ética- ensaio sociofilosófico, Brasília, OAB Editora, 2004; HANS JONAS, Técnica, medicina y ética- Sobre la práctica del principio de responsabilidade, Traducción de Carlos Fortea Gil, Barcelona, Paidós, 1997. Título original: Technik, Medizin und Ethik. Zur Praxis des Prinzips Veranticortung; CELSO LAFER, "A MENTIRA- Um capítulo das relações entre a ética e a política". En NOVAES, Adauto (org.), Ética, São Paulo, Companhia das Letras/Secretaria Municipal de Cultura, 1992; HERMES LIMA, Introdução à ciência do direito. $11^{\text {a }}$ edición, Rio de Janeiro, Freitas Bastos, 1961; OSVALDO FERREIRA DE MELO, "Ética e Direito" Em: NEJ. Vol.11, n.1 -p.35-39/jan-jun 2006; OSVALDO FERREIRA DE MELO, Dicionário de Política Jurídica, Florianópolis, OAB/SC Editora, 2000; CHAÏM PERELMAN, Ética e Direito, Traducción de Maria Ermantina Galvão G. Pereira, São Paulo, Martins Fontes, 1966. Título original: Éthique et Droit; MIGUEL REALE, Lições Preliminares de Direito, 10a edición, São Paulo, Saraiva,1983; SÉRGIO PAULO ROUANET, "Dilemas da Moral Iluminista" En NOVAES, Adauto (org.), Ética, São Paulo, Companhia das Letras/Secretaria Municipal de Cultura, 1992, p. 149 a 162; PETER SINGER, Vida Ética- Os melhores ensaios do mais polêmico filósofo da atualidade, Traducción de Alice Xavier, Rio de Janeiro, Ediouro, 2002. Título original: Writings on na ethical life; ERNST TUGENDHAT, Lições sobre Ética, $3^{a}$ edición, Traducción de Róbson Ramos dos Reis, et all, Petrópolis, Vozes, 1996. Título original: Vorlesungen über Ethik; NORBERT WIENER, Cibernética e Sociedade, Traducción de José Paulo Paes, 7a edición, São Paulo, Cultrix, 2000. Título original: The Human use of Human Beings.

9 Conforme consta en: CESAR LUIZ PASOLD, Personalidade e Comunicação, 2a edición, Florianópolis, Plus Saber Editora, 2005, p.99. También en: CESAR LUIZ PASOLD, O advogado e a advocacia, $3^{a}$ edición, Florianópolis, OAB/SC Editora, 2001, p.141. 
PASOLD, Cesar Luiz. El Taedium Vitae De Norberto Bobbio Y La Ética Médica. Revista Eletrônica Direito e Política, Programa de Pós-Graduação Stricto Sensu em Ciência Jurídica da UNIVALI, Itajaí, v.11, n.1, $1^{0}$ quadrimestre de 2016. Disponível em: www.univali.br/direitoepolitica - ISSN 1980-7791.

elemento valorizador, calificador y atribuidor de efectos a un comportamiento, con el objetivo de que sean aseguradas adecuadamente la organización de las relaciones humanas y la justa convivencia, habiendo conferido la Sociedad al Estado el necesario poder coercitivo para la preservación del orden jurídico y la realización de la Justicia ${ }^{10}$.

En este artículo no se aborda la cuestión en debate ni desde el ángulo de la Moral ni del Derecho. Así, establecidos los conceptos operacionales distintos para Ética, Moral y Derecho, el presente artículo prosigue ofreciendo un panorama de la fructífera vida intelectual y científica de Norberto Bobbio, es decir, viéndolo en su historia como profesor, científico, jurista y filósofo. Tal descripción sirve para contribuir a la mejor comprensión del Taedium Vitae que Bobbio sintió cuando no tenía más condiciones físicas de producir intelectualmente ni de participar activamente en eventos científicos y culturales.

\section{La Muerte y la síntesis de la Vida Profesional de Bobbio}

El 9 de enero de 2004, en Turín, Italia, falleció NORBERTO BOBBIO, a los 94 años. Profesor, Filósofo, Teórico y Científico Político, Jurista, autor de muchos libros dotados de elevada calidad descriptiva, histórica, analítica e inspiradores de estudios de reflexión y de crítica científicamente responsable. Su hijo, el cardiólogo Marco Bobbio, informó que el padre "en los últimos tres meses de vida repetía con frecuencia la expresión latina taedium vitae para decir que estaba cansado de la vida"11.

¿Bien, qué vida tuvo Norberto Bobbio? ¿Y qué es lo que en ella puede haberlo llevado a sentir más aún el tedio cuando ya estaba anciano, intelectualmente

${ }^{10}$ Conforme propuesto originalmente en CESAR LUIZ PASOLD, Prática da Pesquisa Jurídica e Metodologia da Pesquisa Jurídica, 10a edición, Florianópolis, OAB/SC Editora, 2007, p. 80. (negrito en el original).

${ }^{11}$ En MARCO BOBBIO, Moderação e Serenidade, Entrevista para Adriana Dias Lopes, revista Veja-edição 2402, ano 47, n049, 03/12/2014, p.17 a 22. 
PASOLD, Cesar Luiz. El Taedium Vitae De Norberto Bobbio Y La Ética Médica. Revista Eletrônica Direito e Política, Programa de Pós-Graduação Stricto Sensu em Ciência Jurídica da UNIVALI, Itajaí, v.11, n.1, $1^{0}$ quadrimestre de 2016. Disponível em: www.univali.br/direitoepolitica - ISSN 1980-7791.

improductivo y aislado en su casa? Estas indagaciones son relevantes en la medida en que sus respuestas puedan dar base a reflexiones éticas sobre la muerte del Jurista y sus circunstancias. Se presenta a seguir un panorama de la Vida y Obra de Norberto Bobbio ${ }^{12}$, optando por la descripción de algunos detalles y momentos que, a juicio del autor de este artículo, y salvo mejor parecer, puedan estimular reflexiones conducentes a los propósitos del presente texto.

Bobbio nació el 18 de octubre de 1909 en Turín, un día antes del fallecimiento de Cesare Lombroso, que Norberto insistía en definir como "docente de Medicina Legal y de Higiene Pública en la Universidad de Turín"13. Bobbio era hijo de Luigi Bobbio, médico cirujano, y de Rosa Caviglia. Su ingreso en la Universidad de Turín ocurrió en 1927, específicamente en la Facultad de Jurisprudencia, y entre sus Profesores se destaca aquí el nombre de Gioele Solari, que fue su orientador en la "tesis sobre Filosofía del Derecho y Ciencia del Derecho en $1931^{\prime 14}$. Dos años más tarde, más precisamente en julio de 1933, obtuvo su "segundo diploma"15, ahora en Filosofía, cuya tesis de conclusión trató sobre la Fenomenología de Husserl. En el mes de marzo de 1934 conquistó la libre docencia en Filosofía del Derecho, con una "memoria"

12 Aquí se realiza un desafiador ejercicio de síntesis del Capítulo "NORBERTO BOBBIO: UM RETRATO NECESSÁRIO", expuesto por entero en: CESAR LUIZ PASOLD, Ensaio sobre a Ética de Norberto Bobbio, Florianópolis, Conceito Editorial, 2008, p.31 a 149. Se mantienen ciertas transcripciones literales $y$, evidentemente, reportadas sus fuentes en notas de pie de página, puesto que contribuyen mucho para comprender la personalidad histórica de Bobbio y la riqueza intelectual de su vida.

13 NORBERTO BOBBIO, Diário de um século: Autobiografia, Traducción de Daniela Beccaccia Versiani, Rio de Janeiro, Campus, 1998. Título original: Autobiografia. p. 2.

${ }^{14}$ PIETRO POLITO (org.), "Notas biográficas" En BOBBIO, Norberto, 0 tempo da memória. De senectute e outros escritos autobiográficos, Traducción Daniela Versiani, Rio de Janeiro, Campus, 1997. Título original: De senectute. p. 184. Vide, también, JOSÉ FERNÁNDEZ SANTILLÁN, "Apresentação- Biografia e história" En BOBBIO, Norberto, (org. José Fernández Santillán), Norberto Bobbio: o filósofo e a política, Traducción de Cesar Benjamin e Vera Ribeiro, Rio de Janeiro, Contraponto, 2003. Título original: Norberto Bobbio: el filosofo y la politica. p. 16. Y vide más: NORBERTO BOBBIO, "Prefazione". en VIOLI, Carlo (org.). Bibliografia degli scritti di Norberto Bobbio. 1934-199,. Roma, Gius.Laterza \& Figli, 1995, p. XXXI.

15 Vide NORBERTO BOBBIO, Diário de um século: Autobiografia, Traducción de Daniela Beccaccia Versiani, Rio de Janeiro, Campus, 1998. Título original: Autobiografia, p. 16. 
PASOLD, Cesar Luiz. El Taedium Vitae De Norberto Bobbio Y La Ética Médica. Revista Eletrônica Direito e Política, Programa de Pós-Graduação Stricto Sensu em Ciência Jurídica da UNIVALI, Itajaí, v.11, n.1, $1^{0}$ quadrimestre de 2016. Disponível em: www.univali.br/direitoepolitica - ISSN 1980-7791.

orientada al Indirizzo fenomenológico nella filosofia sociale e giuridica ${ }^{16}$. En 1935 Bobbio asciende a la función en la Universidad Libre de Camerino": impartió clase a partir del mes de noviembre y permaneció en esta Institución hasta $1938^{17}$, llegando a ser Secretario de la Facultad y después Director del Círculo Jurídico, "que era la biblioteca de la Facultad"18. El 15 de mayo de 1935 fue preso junto con amigos que integraban el grupo denominado "Justicia y Libertad". Ese mismo año escribió y envió una carta - documento que acabaría por transformarse en uno de los dos momentos ideológicos más polémicos de su existencia - al Dictador del Gobierno fascista de Italia, a Benito Mussolini. En ella, entre otros momentos, dice ser poseedor de "consciencia fascista", "que estaría siendo ofendida por acusaciones que en aquella época circulaban en la policía política, de que él, Bobbio, sería antifascista"19. Más tarde se retractaría de ello. En 1937, pasando sus vacaciones en Berlín, aprovechó para completar un estudio sobre Max Scheler, concluyendo sus investigaciones sobre la fenomenología, corporificado en el artículo denominado "La personalitá di Max Scheler". En aquel momento ocurrió algo muy importante para la vida de Bobbio, como Científico del Derecho: conoció a Carl Schmitt, por quien fue recibido con simpatía en una cena. Hubo una larga conversación, al final de la cual Schmitt le regaló a Bobbio algunos libros. Se registró un significativo intercambio de correspondencia entre los dos entre 1948 y 1953, y también en 1980. En 1938 sucedió un nuevo hecho que tuvo repercusiones de orden ideológica, pues Bobbio se inscribió para el cargo de profesor titular en Siena. Surgieron obstáculos originados en la burocracia estatal, ahora en virtud de su participación en actividades antifascistas. Estas restricciones le

16 Conforme el registro de PIETRO ROSSI, "Introduzione" En ZAGREBESLKY, Gustavo; et ali, Norberto Bobbio tra diritto e política, Roma, Editori Laterza, 2005. p. VI.

17 ALAÔR CAFFÉ ALVES, "Apresentação". en BOBBIO, Norberto, Teoria da norma jurídica, Traducción de Fernando Pavan Baptista e Ariani Bueno Studatti, $2^{\circ}$ edición, Bauru, Edipro, 2003. Título original: Teoria della norma giuridica.p.9.

18 NORBERTO BOBBIO, 0 tempo da memória. De senectute e outros escritos autobiográficos, Traducción Daniela Versiani, Rio de Janeiro, Campus, 1997. Título original: De senectute, p.186.

19 NORBERTO BOBBIO, Diário de um século: Autobiografia, Traducción de Daniela Beccaccia Versiani, Rio de Janeiro, Campus, 1998. Título original: Autobiografia, p. 28. 
PASOLD, Cesar Luiz. El Taedium Vitae De Norberto Bobbio Y La Ética Médica. Revista Eletrônica Direito e Política, Programa de Pós-Graduação Stricto Sensu em Ciência Jurídica da UNIVALI, Itajaí, v.11, n.1, $1^{0}$ quadrimestre de 2016. Disponível em: www.univali.br/direitoepolitica - ISSN 1980-7791.

provocaron a Bobbio una gran indignación. Emocionado, se dirige a un tío General que era amigo de Emilio De Bono, que tenía relaciones próximas a Mussolini. De Bono le envía una carta al Jefe de Gobierno alegando a favor de Bobbio (el general) y de Bobbio (el sobrino), Norberto ${ }^{20}$. Por mérito venció el concurso, y superados los obstáculos permaneció en la Universidad de Siena ejerciendo el magisterio de enero de $1939{ }^{21}$ hasta 1940 . Es preciso registrar que su tesis de concurso fue dedicada al examen de "A analogia na lógica do

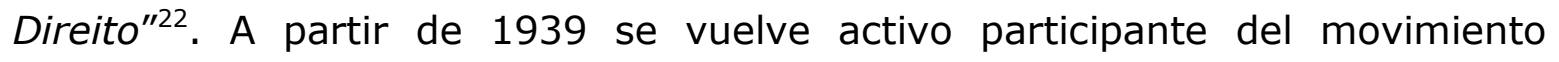
italiano antifascista, participando en las reuniones del movimiento liberal socialista. $\mathrm{Y}$ es en este último que se dedica por primera vez al estudio de Thomas Hobbes, haciendo una interesante reseña (publicada en la Rivista di filosofia ${ }^{23}$ ) del ensayo de Carl Schmitt sobre el Leviatán.

De diciembre de 1940 a 1948, Bobbio se desempeñó en la Facultad de Jurisprudencia de la Universidad de Padua, enseñando Filosofía del Derecho, y como Secretario de la Facultad a lo largo de ocho años ${ }^{24}$. De 1940 a 1942 se formó el Partito d'Azione (Partido de la Acción), ${ }^{25}$ hecho muy relevante en la vida de Bobbio, porque esta fue la única agremiación político partidaria que él integró como afiliado, sin permanecer por mucho tiempo en esa condición,

\footnotetext{
${ }^{20}$ La carta se encuentra en portugués en las páginas 33 y 34 de NORBERTO BOBBIO, Diário de um século: Autobiografia, Traducción de Daniela Beccaccia Versiani, Rio de Janeiro, Campus, 1998. Título original: Autobiografia.
}

${ }^{21}$ PIETRO POLITO (org.), "Notas biográficas" En BOBBIO, Norberto, 0 tempo da memória. De senectute e outros escritos autobiográficos, Traducción Daniela Versiani, Rio de Janeiro, Campus, 1997. Título original: De senectute. p. 186.

22 CELSO LAFER, "Um professor: a autobiografia de Bobbio" En CARDIN, Carlos Henrique (org.), Bobbio no Brasil - um retrato intelectual, Brasília, Editora Universidade de Brasília; São Paulo: Imprensa Oficial do Estado, 2001, p.83.

23 NORBERTO BOBBio, "Premissa". en BOBBIO, Norberto, Thomas Hobbes, Traducción de Carlos Nélson Coutinho, Rio de Janeiro, Campus, 1991. Título original: Thomas Hobbes, p. I.

${ }^{24}$ NORBERTO BOBBIO, O tempo da memória. De senectute e outros escritos autobiográficos, Traducción Daniela Versiani, Rio de Janeiro, Campus, 1997. Título original: De senectute. p.80.

${ }^{25}$ Debe registrarse que mucho más tarde, en 1966, Bobbio viviría su segundo momento de relación con un Partido Político, compareciendo al Palacio de Deportes de Roma, "tomado por una multitud", y apoyando la XXXVII Convención del PSI y la XV Convención del PSDI que decidieron la unificación, dando nacimiento al PSU (Partido Socialista Unificado). 
PASOLD, Cesar Luiz. El Taedium Vitae De Norberto Bobbio Y La Ética Médica. Revista Eletrônica Direito e Política, Programa de Pós-Graduação Stricto Sensu em Ciência Jurídica da UNIVALI, Itajaí, v.11, n.1, $1^{0}$ quadrimestre de 2016. Disponível em: www.univali.br/direitoepolitica - ISSN 1980-7791.

pues adhirió en octubre de 1942 y no por mucho tiempo. Fue militante en la clandestinidad e integró la resistencia, permaneciendo "al lado de los comunistas", pues él entendía la lucha de liberación del fascismo como una preliminar de una "rivoluzione democrática" 26 y no una especie de lucha de clases. El $1^{\circ}$ de enero de 1942 fue nombrado Profesor Titular en la Universidad de Padua ${ }^{27}$. Bobbio se casó en 1943, el día 28 de abril, con Valéria Cova, que llegaría a ser su compañera extraordinaria. El fascismo cayó el 25 de julio de ese año. El 26 de julio Bobbio fue a Milán, participó en las manifestaciones populares de apoyo a la caída del fascismo e integró activamente los debates sobre las manifestaciones de tres partidos políticos. La ocupación alemana en Italia duró de setiembre de 1943 a abril de 1945. En ese período Bobbio, recogido, se dedicó a estudios y lecturas reflexivas, especialmente de "obras editadas e inéditas de Carlo Cattaneo", autor que Bobbio calificaría como su segundo maestro, inmediatamente después de Croce, a quien siempre consideró como su mayor maestro. Es importante registrar que del 6 de diciembre de 1943 hasta fines de febrero de 1944, Bobbio estuvo preso en el cuartel de la policía política republicana, en la ciudad de Padua, porque era considerado integrante del "Comité de Acción por la Liberación de Italia", considerada como una asociación secreta antifascista. ${ }^{28}$ En 1944 se registran dos destaques de publicaciones de Bobbio. En setiembre de 1944 circula el primer número del diario L'Ora dell 'Azione, prácticamente por completo con escritos de Bobbio, con destaque para lo que él siempre consideró como su "primer artículo político", intitulado "Esclarecimiento". En él postulaba que "los intelectuales deberían huir de dos comportamientos, ambos negativos: la politiquería, es decir, el empeño en la política con fines personales, y la

\footnotetext{
26 NORBERTO BOBBIO, "Autobiografia Intellettuale". en VIOLI, Carlo (org.). Bibliografia degli scritti di Norberto Bobbio. 1934-1993, Roma, Gius.Laterza \& Figli, 1995, p. XI e XII.

27 PIETRO POLITO (org.), "Notas biográficas" En BOBBIO, Norberto, 0 tempo da memória. De senectute e outros escritos autobiográficos, Traducción Daniela Versiani, Rio de Janeiro, Campus, 1997. Título original: De senectute. p. 186.

28 NORBERTO BOBBIO, Diário de um século: Autobiografia, Traducción de Daniela Beccaccia Versiani, Rio de Janeiro, Campus, 1998. Título original: Autobiografia. p. 1 y 2.
} 
PASOLD, Cesar Luiz. El Taedium Vitae De Norberto Bobbio Y La Ética Médica. Revista Eletrônica Direito e Política, Programa de Pós-Graduação Stricto Sensu em Ciência Jurídica da UNIVALI, Itajaí, v.11, n.1, $1^{0}$ quadrimestre de 2016. Disponível em: www.univali.br/direitoepolitica - ISSN 1980-7791.

apolítica, entendida como indiferencia por la política"29. El segundo destaque de ese año es que la Editorial Schiantore lanzó su libro intitulado "La Filosofía del Decadentismo", obra que recibió traducción al inglés en 1948 y al castellano en 1949. A fines de 1945 hizo un viaje a Inglaterra, donde conoció a Harold J. Laske, científico político y miembro del Partido Laborista inglés. El 2 de junio de 1946, Bobbio fue candidato a la Asamblea Constituyente italiana por el Partido de la Acción. No se eligió y su Partido obtuvo apenas el 1,5\% de Ios votos; quien obtuvo la victoria fue la Democracia Cristiana con el 35,2\% Bobbio consideró importante aquello que llamó el "arranque de la transformación democrática del país". ${ }^{31}$ Los cinco años que van de 1945 a 1950 fueron muy productivos, en especial porque Bobbio escribió artículos y ensayos sobre el tema federalismo, y pronunció conferencias y cursos sobre el pacifismo y su historia. ${ }^{32}$ Precisamente en 1946 Bobbio aceptó la invitación del Rector de la Universidad de Padua, y como Italia estaba por fin liberada de la tutela fascista, profirió la clase que inauguró el año Académico con el tema "La

${ }^{29}$ PIETRO POLITO (org.), "Notas biográficas" En BOBBIO, Norberto, 0 tempo da memória. De senectute e outros escritos autobiográficos, Traducción Daniela Versiani, Rio de Janeiro, Campus, 1997. Título original: De senectute. p. 187.

30 NORBERTO BOBBIO, Diário de um século: Autobiografia, Traducción de Daniela Beccaccia Versiani, Rio de Janeiro, Campus, 1998. Título original: Autobiografia. p. 76. También en PIETRO POLITO (org.), "Notas biográficas" En BOBBIO, Norberto, 0 tempo da memória. De senectute e outros escritos autobiográficos, Traducción Daniela Versiani, Rio de Janeiro, Campus, 1997. Título original: De senectute. p. 187.

31 Traducción libre del autor del presente libro del siguiente texto en español: "Después de la liberación y del arranque de la transformación democrática del país, desvanecida la ilusión de la unidad de política y cultura, descubierto el error del compromiso inmediatamente político del intelectual, la vieja y ya anacrónica figura del educador ha venido siendo sustituida poco a poco por la del hombre de letras y de ciencias, cuya tarea debería ser la de dar su contribución específica, que es sobre todo una contribución de conocimiento, a la percepción, a la aclaración, a las posibles soluciones de los problemas de la época, en una situación en la que no se trataba tanto de hacer a los italianos como de rehacer Italia." Conforme NORBERTO BOBBIO, Perfil ideologico del siglo XX en Italia, Traducción para o español de Stella Mastrangelo, MéxicoDF, Fondo de Cultura Económica, 1993. Título original: Profilo ideologico del Novecento italiano, p. 13.

32 NORBERTO BOBBIO, "Prefácio à primeira edição italiana". en BOBBIO, Norberto, o problema da guerra e as vias da paz, Traducción de Álvaro Lorencini São Paulo Editora UNESP, 2003. Título original: Il problema della guerra e le vie della pace. p. 40. 
PASOLD, Cesar Luiz. El Taedium Vitae De Norberto Bobbio Y La Ética Médica. Revista Eletrônica Direito e Política, Programa de Pós-Graduação Stricto Sensu em Ciência Jurídica da UNIVALI, Itajaí, v.11, n.1, $1^{0}$ quadrimestre de 2016. Disponível em: www.univali.br/direitoepolitica - ISSN 1980-7791.

persona y el Estado"33. También en 1946, consagrando lo que Bobbio denominaba "caminata progresiva de la democracia", "se eliminó la discriminación de los sexos" en Italia, consagrándose el "sufragio universal, sin restricciones" 34 . Bobbio era contrario al ausentismo electoral y por ello aprobó la Ley no 1058 que en uno de sus artículos preveía una pena considerada "leve" para los electores que se abstuviesen de votar en las elecciones para las Cámaras de Diputados. ${ }^{35}$ A fines de marzo de 1948 ocurrió un hecho muy importante en la vida académica de Bobbio, pues fue nombrado Profesor Titular en Filosofía del Derecho por la Universidad de Turín ${ }^{36}$, ejerciendo el magisterio en la cátedra de Filosofía del Derecho hasta 1972. Considerando que de 1973 a 1984 - año en el que fue jubilado como Profesor Emérito también ocupó una cátedra, pero entonces en la asignatura de Filosofía Política en la Facultad de Ciencias Políticas ${ }^{37}$, sucediendo a Alessandro Passserin

33 NORBERTO BOBBIO, "Premissa". en BOBBIO, Norberto, Thomas Hobbes, Traducción de Carlos Nélson Coutinho, Rio de Janeiro, Campus, 1991. Título original: Thomas Hobbes. p. I. También en NORBERTO BOBBIO, o tempo da memória. De senectute e outros escritos autobiográficos, Traducción Daniela Versiani, Rio de Janeiro, Campus, 1997. Título original: De senectute. p. 92. Y, vide también: NORBERTO BOBBIO, "Prefazione". en VIOLI, Carlo (org.). Bibliografia degli scritti di Norberto Bobbio. 1934-199,. Roma, Gius.Laterza \& Figli, 1995, p. XXVIII.

${ }^{34}$ Vide manifestación de Bobbio en: CARLOS HENRIQUE CARDIN (org.), Bobbio no Brasil - um retrato intelectual, Brasília, Editora Universidade de Brasília; São Paulo, Imprensa Oficial do Estado, 2001. Título original: Autobiografia. p. 40 y 41.

${ }^{35}$ En este caso, la pena prevista era la inscripción en una lista "expuesta durante un mes en el mural del ayuntamiento", y si la abstención se prolongase por cinco años seguidos, la pena sería la "notificación del hecho en los certificados de buena conducta": conforme NORBERTO BOBBIO, Entre duas Repúblicas: as origens da democracia italiana, Traducción de Mabel Malheiros Bellati, São Paulo, Imprensa Oficial do Estado, 2001. Título original: Tra due repubblichi- Alle origini della democrazia italiana. p.110.

${ }^{36}$ Conforme PIETRO POLITO (org.), "Notas biográficas" En BOBBIO, Norberto, o tempo da memória. De senectute e outros escritos autobiográficos, Traducción Daniela Versiani, Rio de Janeiro, Campus, 1997. Título original: De senectute. p. 188.

37 Vide ALAÔR CAFFÉ ALVES, "Apresentação". en BOBBIO, Norberto, Teoria da norma jurídica, Traducción de Fernando Pavan Baptista e Ariani Bueno Studatti, $2^{\circ}$ edición, Bauru, Edipro, 2003. Título original: Teoria della norma giuridica. p. 9. 
PASOLD, Cesar Luiz. El Taedium Vitae De Norberto Bobbio Y La Ética Médica. Revista Eletrônica Direito e Política, Programa de Pós-Graduação Stricto Sensu em Ciência Jurídica da UNIVALI, Itajaí, v.11, n.1, $1^{0}$ quadrimestre de 2016. Disponível em: www.univali.br/direitoepolitica - ISSN 1980-7791.

d'Entreves ${ }^{38}$, Bobbio se mantuvo vinculado, activo y productivo, durante 36 años a la Universidad de Turín.

En mayo de 1950 fue fundada en Venecia, liderada por Umberto Campagnolo, la "Sociedad Europea de Cultura - SEC", de la cual Bobbio fue uno de sus fundadores y después presidente honorario. Su objetivo era la unión de "hombres de cultura por medio de vínculos de solidaridad y amistad". La adhesión a la Sociedad contó con nombres significativos de la intelectualidad de la época, como por ejemplo Thomas Mann, Urs von Balthazar, Sir Haldane, Antyonio Banfi, Henri Lefebbre, André Sigfried y Stephen Spender ${ }^{39}$. En 1950 también fue elegido Presidente del Centro del libro popular, cargo que ejerció durante seis años ${ }^{40}$. A partir también de 1952, con Nicola Abbagnano, dirigió la Rivista di filosofia. En el mismo año ocupó la Accademia della scienze di Torino $^{41}$. En 1953 recibió una invitación de Chaim Perelman, que él aceptó, para participar en el Congreso Internacional de Lógica Jurídica, que Bobbio consideró como su "primera participación, aún muy tímida, en un congreso internacional"42. Todavía en 1953 llegó a ser director (cargo que ocupó per alcuni anni) del Istituto di Scienze politiche "Gioele Solari" de la Universidad de Turín $^{43}$. En 1954 fue publicado su primer ensayo sobre Kelsen, autor de su

38 NORBERTO BOBBIO, o tempo da memória. De senectute e outros escritos autobiográficos, Traducción Daniela Versiani, Rio de Janeiro, Campus, 1997. Título original: De senectute. p. 138.

39 NORBERTO BOBBIO, o tempo da memória. De senectute e outros escritos autobiográficos, Traducción Daniela Versiani, Rio de Janeiro, Campus, 1997. Título original: De senectute. p. 110 y 111.

${ }^{40}$ Conforme CARLO VIOLI (org.), Bibliografia degli scritti di Norberto Bobbio. 1934-1993, Roma, Gius.Laterza \& Figli, 1995, p. XXXIV.

${ }^{41}$ NORBERTO BOBBIO, Contribuicion ala teoría del derecho, Traducción para o español de Afonso Ruiz Miguel, Madri, Editorial Debate, 1990.

42 NORBERTO BOBBIO, O tempo da memória. De senectute e outros escritos autobiográficos, Traducción Daniela Versiani, Rio de Janeiro, Campus, 1997. Título original: De senectute. p. 16. Y, vide PIETRO POLITO (org.), "Notas biográficas" En BOBBIO, Norberto, O tempo da memória. De senectute e outros escritos autobiográficos, Traducción Daniela Versiani, Rio de Janeiro, Campus, 1997. Título original: De senectute. p. 189. Y, vide también: NORBERTO BOBBIO, "Autobiografia Intellettuale". en VIOLI, Carlo (org.). Bibliografia degli scritti di Norberto Bobbio. 1934-1993, Roma, Gius.Laterza \& Figli, 1995, p. IX.

43 CARLO VIOLI (org.), Bibliografia degli scritti di Norberto Bobbio. 1934-1993, Roma, Gius.Laterza \& Figli, 1995, p. XXXIIV. 
PASOLD, Cesar Luiz. El Taedium Vitae De Norberto Bobbio Y La Ética Médica. Revista Eletrônica Direito e Política, Programa de Pós-Graduação Stricto Sensu em Ciência Jurídica da UNIVALI, Itajaí, v.11, n.1, $1^{0}$ quadrimestre de 2016. Disponível em: www.univali.br/direitoepolitica - ISSN 1980-7791.

confesada especial admiración. Es más, Bobbio afirmó explícitamente que se convirtió al "kelsenismo" cuando, hacía muchos años, se había dedicado al estudio y comentarios sobre la Teoría del Derecho del clásico Carnelutti ${ }^{44}$. En 1955, con la China ya bajo la dominación de Mao Tsé Tung, una delegación italiana fue invitada y realizó una visita a ese país, con la participación de Bobbio en calidad de invitado, en un viaje que duró un mes. El comentario de Bobbio sobre este viaje es contundente: "fue un viaje inolvidable, que me marcó profundamente. Si el viaje a Inglaterra significó el descubrimiento de la Democracia, el viaje a la China representó mi encuentro con el comunismo real $^{\prime 45}$. En 1956 Bobbio tuvo otro momento delicado en su vida como intelectual y científico. Es que en ese año, en febrero, Kruschev discursó en el XX० Congreso del Partido Comunista de la Unión Soviética, publicando los horrores del régimen liderado por Stalin. La revista italiana Nuovi Argumenti eligió a Bobbio - considerado como uno de los intelectuales de izquierda invitándolo a contestar a nueve preguntas sobre el tema. Sus respuestas tuvieron gran repercusión y provocaron polémica. Hubo un debate, y cuando el asunto se extinguió, Bobbio guardó silencio por 20 años sobre el tema. Solamente volvió a publicar ideas a respecto de "marxismo y estado" cerca de 20 años después, en una de sus obras consideradas hoy como clásicas, intitulada "¿Qué Socialismo?". Todavía en 1956 fue publicada en Turín la "primera traducción completa de los escritos políticos y jurídicos de Kant, en la colección de los 'Clásicos Políticos de la Utet': Immanuel Kant, Scritti politici e di filosofia della storia e del diritto, con traducciones de Gioele Solari y Giovanni Vidari. La edición fue póstuma y tuvo la efectiva colaboración de Bobbio $^{46}$. En el año 1957 tuvo lugar el lanzamiento de la primera edición de

44 Conforme NORBERTO BOBBIO, "Autobiografia Intellettuale". en VIOLI, Carlo (org.). Bibliografia degli scritti di Norberto Bobbio. 1934-1993, Roma, Gius.Laterza \& Figli, 1995, p. V.

45 NORBERTO BOBBIO, Diário de um século: Autobiografia, Traducción de Daniela Beccaccia Versiani, Rio de Janeiro, Campus, 1998. Título original: Autobiografia. p 102.

${ }^{46}$ BOBBIO, Norberto, "Prefácio à segunda edição". en BOBBIO, Norberto, Direito e estado no pensamento de Emanuel Kant, Traducción de Alfredo Fait, Brasília, Editora Universidade de Brasília, 1984. Título original: Diritto e Stato nel Pensiero di Emanuele Kant, p.9. 
PASOLD, Cesar Luiz. El Taedium Vitae De Norberto Bobbio Y La Ética Médica. Revista Eletrônica Direito e Política, Programa de Pós-Graduação Stricto Sensu em Ciência Jurídica da UNIVALI, Itajaí, v.11, n.1, $1^{0}$ quadrimestre de 2016. Disponível em: www.univali.br/direitoepolitica - ISSN 1980-7791.

"Diritto e Stato nel Pensiero di Emanuele Kant". En nuestro país ese importante texto fue publicado en el año 1984 con el título, en traducción literal al portugués, como: "Direito e estado no pensamento de Emanuel Kant"47. En ese mismo año, otro momento especialmente significativo para Bobbio: su único encuentro personal con Hans Kelsen, ocurrido el 22 y 23 de junio en París, en el primer congreso del Institut International de Philosophie Politique. El tema del evento era Derecho Natural, y Bobbio pronunció una conferencia con el título Quelques arguments contre le droit naturel ${ }^{48}$. También en ese año estuvo en los coloquios del "Centre Nacional de Recherche de Logique", promoción de Chaim Perelmann, en la ciudad de Bruselas. Estuvo, además, en el congreso del vigésimo año de la muerte de Gramsci. Este autor, a propósito, fue objeto de investigaciones profundas de Bobbio, cuidando "principalmente de tres temas: la dialéctica, la sociedad civil, el esbozo de una posible teoría política (a ser reconstruida)". Diez años después, en 1967, y veinte años después (1987), respectivamente en los trigésimo y quincuagésimo aniversario de la muerte de Gramsci, Bobbio pontificó con escritos sobre este ideólogo importantísimo para la Teoría Política italiana y mundial. ${ }^{49}$. Retornando al año 1957, debe ser registrado que en esa fecha y en 1958, en la Universidad de Turín, Bobbio impartió el curso "Teoría de la Norma Jurídica". Los textos al respecto dieron origen al libro homónimo ${ }^{50}$. En el mismo bienio salió a la luz la "Teoría del Ordenamiento Jurídico" ${ }^{51}$, escrito para la asignatura denominada

\footnotetext{
47 Vide el indicado en la nota de pie de página anterior.

48 PIETRO POLITO (org.), "Notas biográficas" En BOBBIO, Norberto, O tempo da memória. De senectute e outros escritos autobiográficos, Traducción Daniela Versiani, Rio de Janeiro, Campus, 1997. Título original: De senectute. p. 190.
}
${ }^{49}$ NORBERTO BOBBIO, Ensaios sobre Gramsci e o Conceito de Sociedade Civil, Traducción de Marco Aurélio Nogueira e Carlos Nélson Coutinho, São Paulo, Paz e Terra, 1999. Título original: Saggi su Gramsci, p. 12.

50 Versión brasileña: NORBERTO BOBBIO, Teoria da norma jurídica, Traducción de Fernando Pavan Baptista e Ariani Bueno Studatti, 2a edición, Bauru, Edipro, 2003, 192 p. Título original: Teoria della norma giuridica.

51 Versión brasileña: NORBERTO BOBBIO, Teoria do Ordenamento Jurídico, Traducción de Maria Celeste Cordeiro Leite dos Santos. 10a edición, Brasília, Editora Universidade de Brasília, 1999. Título original: Teoria dell 'ordinamento giuridico. 
PASOLD, Cesar Luiz. El Taedium Vitae De Norberto Bobbio Y La Ética Médica. Revista Eletrônica Direito e Política, Programa de Pós-Graduação Stricto Sensu em Ciência Jurídica da UNIVALI, Itajaí, v.11, n.1, $1^{0}$ quadrimestre de 2016. Disponível em: www.univali.br/direitoepolitica - ISSN 1980-7791.

Filosofía del Derecho que, como Bobbio insistía en enfatizar, "era materia del primer año de Derecho"52. En 1959 se registran dos eventos importantes. El primero, en noviembre, es su participación en el IV Congreso Mundial de Sociología, realizado en Stresa, y en el cual pronunció una conferencia sobre "La teoria della classe política negli scrittori democratici in Itália"53.

El año 1960 también reconoce momentos relevantes en la productiva vida intelectual de Bobbio. En julio, Bobbio, Alessandro Passerin d'Entrèves y Renato Treves, presentaron una invitación a los Profesores Herbert Lionel Adolphus Hart y Alf Niels Christian Ross para que participen en un seminario sobre el positivismo jurídico" que, patrocinado por la Rockefeller Foundation, tuvo lugar en la Villa Serbelloni di Bellagio ${ }^{54}$. Del 18 al 22 de marzo de ese mismo año de 1960 fue realizado el "XVIII Congresso Nacional da Società Filosófica Italiana, Palermo-Messina", y entre sus comunicaciones introductorias Bobbio pronunció un discurso sobre el tema "Verdad y libertad"55. En el año académico de 1960-1961 Bobbio construyó y presentó lecciones sobre el positivismo jurídico. El 24 de setiembre de 1961 fue realizada, desde la ciudad de Perugia a la de Assis, la Marcha de la Paz, organizada por Aldo Capitini, en un momento en el que "el mundo vivía bajo la pesadilla del equilibrio del terror atómico y se habían construido bombas que, de un lado y del otro, tenían el poder de destruir diez veces la especie humana". Bobbio estuvo en ella, y cuando volvió a Turín se manifestó al respecto en un artículo publicado en la revista Resistenza y que termina con

52 Conforme CELSO LAFER, "Norberto Bobbio, Teoria do Ordenamento Jurídico", en CARDIN, Carlos Henrique (org.), Bobbio no Brasil - um retrato intelectual, Brasília, Editora Universidade de Brasília; São Paulo, Imprensa Oficial do Estado, 2001, p.75.

53 Conforme registros realizados por PIETRO POLITO (org.), "Notas biográficas" En BOBBIO, Norberto, 0 tempo da memória. De senectute e outros escritos autobiográficos, Traducción Daniela Versiani, Rio de Janeiro, Campus, 1997. Título original: De senectute. p. 190 e 191.

54 NORBERTO BOBBIO, "Prefácio à Nova Edição". en BOBBIO, Norberto, O positivismo jurídico: lições de Filosofia do Direito, Traducción de Márcio Pugliesi et ali, São Paulo, Ícone, 1995, p.11.

55 NORBERTO BOBBIO, Elogio da serenidade e outros ensaios morais, Traducción de Marco Aurélio Nogueira, São Paulo, Editora UNESP, 2002. Título original: Elogio della mitezza e altri scritti morali. p. 207. 
PASOLD, Cesar Luiz. El Taedium Vitae De Norberto Bobbio Y La Ética Médica. Revista Eletrônica Direito e Política, Programa de Pós-Graduação Stricto Sensu em Ciência Jurídica da UNIVALI, Itajaí, v.11, n.1, $1^{0}$ quadrimestre de 2016. Disponível em: www.univali.br/direitoepolitica - ISSN 1980-7791.

una propuesta de concepción de la paz como valor mayor: "... la paz es el bien absoluto, condición necesaria para el ejercicio de todos los otros valores" ${ }^{\prime 56}$. En ese año, 1961, y dentro de la misma línea temática, Bobbio redactó, a pedido de la editorial Einaudi, el prefacio de la edición italiana del libro del filósofo alemán Günther Anders intitulada "Essere o non essere. Diario di Hiroshima e Nagasaki", y que contenía la propuesta de "un código moral, que ante la amenaza de aniquilación de la humanidad debería enunciar nuevos deberes, vinculadores de todos los hombres" ${ }^{57}$. Bobbio registra que fue a partir de este libro, cuyo prefacio escribió, que empezó a interesarse por el problema de las nuevas armas y por "aquello que entonces se empezaba a llamar la 'formación de una consciencia atómica""58. Todavía en 1961 llegó a ser Presidente del Centro Studi Piero Gobetti di Torino, cargo que continuaría ocupando hasta el año $1993^{59}$. En 1962, permaneciendo también en Filosofía del Derecho, inició el magisterio de la asignatura académica Ciencia Política, ambas en la Universidad de Turín ${ }^{60}$. En 1964, la Internationale Vereinigung für Rechtsphilosophie promovió en Toulouse el "Coloque de philosophie du droit compare", dedicado al tema "Droit et nature des choses". Bobbio fue invitado por Werner Maihofer para participar, y "presentó una disertación sobre la naturaleza de las cosas en la doctrina italiana"61. En 1965, el Círculo Jurídico

\footnotetext{
${ }^{56}$ In NORBERTO BOBBIO, Diário de um século: Autobiografia, Traducción de Daniela Beccaccia Versiani, Rio de Janeiro, Campus, 1998. Título original: Autobiografia. pp. 205,206 y 207.

57 Conforme NORBERTO BOBBIO, Diário de um século: Autobiografia, Traducción de Daniela Beccaccia Versiani, Rio de Janeiro, Campus, 1998. Título original: Autobiografia. p. 209. En ese momento - 1961-, afirma Bobbio, él comenzó a ocuparse del "tema de la guerra en el área atómica".

${ }^{58}$ Así está en NORBERTO BOBBIO, "Prefácio à primeira edição italiana". en BOBBIO, Norberto, 0 problema da guerra e as vias da paz, Traducción de Álvaro Lorencini São Paulo Editora UNESP, 2003. Título original: Il problema della guerra e le vie della pace. p. 40.
}

59 CARLO VIOLI (org.), Bibliografia degli scritti di Norberto Bobbio. 1934-1993, Roma, Gius.Laterza \& Figli, 1995, p. XXXIV.

60 Conforme CELSO LAFER, "Um professor: a autobiografia de Bobbio" En CARDIN, Carlos Henrique (org.), Bobbio no Brasil - um retrato intelectual, Brasília, Editora Universidade de Brasília; São Paulo: Imprensa Oficial do Estado, 2001, p.84.

61 Conforme PIETRO POLITO (org.), "Notas biográficas" En BOBBIO, Norberto, O tempo da memória. De senectute e outros escritos autobiográficos, Traducción Daniela Versiani, Rio de Janeiro, Campus, 1997. Título original: De senectute. p. 191. 
PASOLD, Cesar Luiz. El Taedium Vitae De Norberto Bobbio Y La Ética Médica. Revista Eletrônica Direito e Política, Programa de Pós-Graduação Stricto Sensu em Ciência Jurídica da UNIVALI, Itajaí, v.11, n.1, $1^{0}$ quadrimestre de 2016. Disponível em: www.univali.br/direitoepolitica - ISSN 1980-7791.

de la Universidad de Siena lanza la primera edición de la Bibliografia degli scritti di Norberto Bobbio (1934-1964), organizada por Carlo Violi62. A partir de 1965 fue socio corresponsal de la British Academy ${ }^{63}$. En el denominado mundo occidental, en 1968 se destacó un hecho caracterizado por manifestaciones estudiantiles, violentas muchas de ellas, que tuvieron lugar en ciudades de diversos países de Europa, y que también ocurrieron en Turín, ciudad en la que Bobbio vivía y trabajaba. Bobbio acabó por vivenciar un momento especial, en la medida en que su hijo primogénito Luigi se destacó como uno de los líderes del movimiento estudiantil, que entró en confrontación con la Administración Universitaria y con los profesores. Bobbio escribió y la revista Resistenza publicó cuatro artículos sobre el delicado momento ${ }^{64}$, en el cual actuó como profesor y como padre. En el mismo año fue constituida por el Ministerio de Instrucción Pública de Italia una Comisión Técnica integrada por Norberto Bobbio (de la Universidad de Turín), Arrigo Boldrini (de la Universidad Católica de Milán) y Beniamino Andreatta (de la Universidad de Bolonia). A ella le fue atribuida la misión de dirigir la nueva Facultad de Sociología de la Universidad de Trento, específicamente en el tiempo de "transición de instituto privado a Facultad del Estado"65. También en 1968, del verano al otoño, Bobbio escribió un conjunto de ensayos para el último volumen de la recopilación Storia della letteratura italiana, por invitación de Natalino Sapegno ${ }^{66}$. Al año siguiente 62 Así registrado por PIETRO POLITO (org.), "Notas biográficas" En BOBBIO, Norberto, o tempo
da memória. De senectute e outros escritos autobiográficos, Traducción Daniela Versiani, Rio de
Janeiro, Campus, 1997. Título original: De senectute. p. 191. Y también en CARLO VIOLI (org.),
Bibliografia degli scritti di Norberto Bobbio. 1934-1993, Roma, Gius. Laterza \& Figli, 1995,
p. XXXVII, nota de pie de página no 2 .

63 Vide CARLO VIOLI (org.), Bibliografia degli scritti di Norberto Bobbio. 1934-1993, Roma, Gius.Laterza \& Figli, 1995, p. XXXIV.

${ }^{64}$ Ver nota $\mathrm{n}^{\circ} 25$ en la p.148 en NORBERTO BOBBIO, Diário de um século: Autobiografia, Traducción de Daniela Beccaccia Versiani, Rio de Janeiro, Campus, 1998. Título original: Autobiografia.

65 Conforme PIETRO POLITO (org.), "Notas biográficas" En BOBBIO, Norberto, O tempo da memória. De senectute e outros escritos autobiográficos, Traducción Daniela Versiani, Rio de Janeiro, Campus, 1997. Título original: De senectute. p. 192.

${ }^{66}$ Así está en NORBERTO BOBBIO, Perfil ideologico del siglo XX en Italia, Traducción para o español de Stella Mastrangelo, México-DF, Fondo de Cultura Económica, 1993. Título original: Profilo ideologico del Novecento italiano, p. 7. 
PASOLD, Cesar Luiz. El Taedium Vitae De Norberto Bobbio Y La Ética Médica. Revista Eletrônica Direito e Política, Programa de Pós-Graduação Stricto Sensu em Ciência Jurídica da UNIVALI, Itajaí, v.11, n.1, $1^{0}$ quadrimestre de 2016. Disponível em: www.univali.br/direitoepolitica - ISSN 1980-7791.

1969 -, fue creada en Turín la Facultad de Ciencias Políticas ${ }^{67}$. En ella Bobbio trabajó por mucho tiempo y con dedicación. En febrero de 1969 Bobbio pronunció en la Casa de Cultura de Milán una conferencia sobre la "desventura" del pensamiento de Carlo Cattaneo, cuya condición de reformador exaltó, especialmente delante de una realidad atemporal. ${ }^{68}$ Aún en 1969, otro momento importante: la revista "De homine" publicó un ensayo con el título "Etica e conflitti di gruppo", de Giuliano Pontara, con cuyo autor Bobbio confesó tener una gran deuda, especialmente por su "iniciación en la ética gandhiana de la no violencia", y cuyo complemento teórico ocurrió en la lectura del libro de este autor, que sería publicado en 1990 con el título Antígone e Creonte, Ética e política nell'a era atômica" ${ }^{69}$.

En 1972 decidió aceptar la invitación de Alessandro Passerin d`Entreves, y asumió la cátedra de Filosofía Política en la Facultad de Ciencias Políticas de la Universidad de Turín, sin ninguna vacilación porque él y Alessandro fueron en distintos momentos, alumnos "del mismo maestro, Gioele Solari, que con la historia de las doctrinas políticas, inició en Italia un ciclo de estudios conducidos mediante riguroso método histórico y con fuerte inspiración filosófica"70. En el año académico de 1972-1973 impartió su primer curso "como titular de la cátedra de Filosofía de la Política", que fue dedicado al tema Società civile e stato", siguiendo diversos otros cursos que sirvieron de base

67 Conforme CELSO LAFER, "Um professor: a autobiografia de Bobbio" En CARDIN, Carlos Henrique (org.), Bobbio no Brasil - um retrato intelectual, Brasília, Editora Universidade de Brasília; São Paulo: Imprensa Oficial do Estado, 2001, p.84 y 85.

68 NORBERTO BOBBIO, Perfil ideologico del siglo XX en Italia, Traducción para o español de Stella Mastrangelo, México-DF, Fondo de Cultura Económica, 1993. Título original: Profilo ideologico del Novecento italiano. p. 284.

${ }^{69}$ NORBERTO BOBBio, (org. Michelangelo Bovero) Teoria Geral da Política: a filosofia política e as lições dos clássicos, Traducción de Daniela Beccaccia Versiani, Rio de Janeiro, Campus, 2002. Título original: Teoria Generale della Politica. p. 263, nota de pie de página no 29 . También en NORBERTO BOBBIO, A Era dos Direitos, Traducción de Carlos Nélson Coutinho, $5^{a}$ reimpresión, Rio de Janeiro, Campus, 1992. Título original: L' Etàt dei Diritti, p.159, nota de final de capítulo no 4.

70 Vide NORBERTO BOBBIO, "Prefácio para a edição brasileira". en BOBBIO, Norberto, A Teoria das Formas de Governo, Traducción de Sérgio Bath, $2^{\text {a }}$ edición, Brasília, Editora Universidade de Brasília, 1980. Título original: La teoria delle forme di governo nella storia del pensiero politico: anno accademico 1975-76. p. IX a XI. 
PASOLD, Cesar Luiz. El Taedium Vitae De Norberto Bobbio Y La Ética Médica. Revista Eletrônica Direito e Política, Programa de Pós-Graduação Stricto Sensu em Ciência Jurídica da UNIVALI, Itajaí, v.11, n.1, $1^{0}$ quadrimestre de 2016. Disponível em: www.univali.br/direitoepolitica - ISSN 1980-7791.

para muchos de sus libros. Ejerció el cargo de Director de la Facultad en el período de 1973 a $1976^{71}$. En el período del 25 al 27 de setiembre de 1972 fue realizado en la Academia Nacional de Lincei "un congreso internacional" para registrar los "cincuenta años de aniversario de la muerte" de Pareto, que fue, confesadamente, uno de los autores predilectos de Bobbio y a respecto de cuyo pensamiento mucho escribió ${ }^{72}$. La paz fue uno de los valores básicos de la ética personal y científica de Bobbio, el principal valor en lo que concierne a sus recomendaciones para una vida política mejor. ${ }^{73}$ Por eso, con mucho placer y convicción, el 15 de setiembre de 1974, en la ciudad de San Remo, impartió la clase inaugural del Curso sobre Derecho Humanitario Internacional. Título de la clase: "La idea de paz y el pacifismo". En ella toma en consideración la relación paz-guerra, ya sea desde el punto de vista conceptual o desde el punto de vista sociológico, y esboza una breve historia de las diversas formas de pacifismo, distinguiéndolas en base a la diferente explicación que cada una de ellas ofrece acerca de la principal causa de las guerras"74. También en 1975 participó en el "Simposio Gramsciano" efectuado en París, donde y cuando fue lanzada la nueva edición francesa de los "Cuadernos de la Cárcel" de Antonio Gramsci. En esa ocasión Bobbio presentó la comunicación intitulada "Lo viejo y lo nuevo en Gramsci"75. En 1976 impartió uno de sus cursos de mayor

71 Vide PIETRO POLITO (org.), "Notas biográficas" En BOBBIO, Norberto, o tempo da memória. De senectute e outros escritos autobiográficos, Traducción Daniela Versiani, Rio de Janeiro, Campus, 1997. Título original: De senectute. p. 193. Específicamente sobre el Curso dedicado al dualismo entre sociedad civil y Estado, y la participación de Michelangelo Bovero en los estudios de esta temática, vide NORBERTO BOBBIO, "Premissa". En BOBBIO, Norberto; BOVERO, Michelangelo, Sociedade e Estado na filosofia política moderna, Traducción de Carlos Nelson Coutinho, $3^{a}$ edición, São Paulo, Brasiliense, 1991. Título original: Società e stato nella filosofia politica moderna, p. 9 y 10.

72 NORBERTO BOBBIO, Ensaios sobre ciência política na Itália, Traducción de Maria Celeste F. Faria Marcondes, Brasília, Editora Universidade de Brasília- São Paulo, Imprensa Oficial do Estado, 2001. Título original: Saggi sulla scienza política in Italia. p.8, nota de pie de página n०1.

73 CESAR LUIZ PASOLD, Ensaio sobre a Ética de Norberto Bobbio, Florianópolis, Conceito Editorial, 2008, p. 232 a 247.

74 NORBERTO BOBBIO, O problema da guerra e as vias da paz, Traducción de Álvaro Lorencini, São Paulo, Editora UNESP, 2003. Título original: Il problema della guerra e le vie della pace. p. 45.

75 NORBERTO BOBBIO, Ensaios sobre Gramsci e o Conceito de Sociedade Civil, Traducción 
PASOLD, Cesar Luiz. El Taedium Vitae De Norberto Bobbio Y La Ética Médica. Revista Eletrônica Direito e Política, Programa de Pós-Graduação Stricto Sensu em Ciência Jurídica da UNIVALI, Itajaí, v.11, n.1, $1^{0}$ quadrimestre de 2016. Disponível em: www.univali.br/direitoepolitica - ISSN 1980-7791.

repercusión, intitulado "La teoría de las formas de gobierno en la historia del pensamiento político", en el que "explora la 'lección de los clásicos', sus temas recurrentes, y la contribución que pueden dar para la comprensión de la actualidad"76. De "fines de 1976 a fines de 1980", colaborando periódicamente en diarios, produjo artículos que serían publicados en La Stampa y en Avanti! Tales textos fueron reunidos y publicados en un libro intitulado Ideologie e il potere in crise ${ }^{77}$. En 1978 la fecha que se destaca es el día 9 de mayo: se trata de un día fatídico porque en él culmina aquella que Bobbio clasifica como la "más temeraria y clamorosa acción terrorista en Italia", con el bárbaro asesinato de Aldo Moro ${ }^{78}$. El 25 de octubre Bobbio pronunció una conferencia que él mismo calificó como "memorable", "en Madrid, en una sala de las Cortes, a invitación del entonces presidente del grupo parlamentario del PSOE (Partido Socialista Obrero Español), Gregorio Peces-Barba Martínez, en los días en los que estaba en curso la aprobación de la nueva Constitución Española". Allí habló de un asunto que en esa época lo preocupaba "mucho" y que también era actual en el país que lo hospedaba: "democracia y socialismo"79. Y hubo otro momento extremadamente importante en la vida de Bobbio: el 16 de mayo de 1979 impartió aquella que él mismo consideró como su "última clase", con la cual concluyó su fructífera "trayectoria como profesor", "...a los

de Marco Aurélio Nogueira e Carlos Nélson Coutinho, São Paulo, Paz e Terra, 1999. Título original: Saggi su Gramsci, p.107, en especial, allí, la primera nota de pie de página.

${ }^{76}$ CELSO LAFER, "Um professor: a autobiografia de Bobbio" En CARDIN, Carlos Henrique (org.), Bobbio no Brasil - um retrato intelectual, Brasília, Editora Universidade de Brasília; São Paulo: Imprensa Oficial do Estado, 2001, p.85. Vide también NORBERTO BOBBIO, "Prefácio". En BOBBIO, Norberto, Estado, governo, sociedade; por uma teoria geral da política, Traducción de Marco Aurélio Nogueira, $2^{\mathrm{a}}$ edición, Rio de Janeiro, Paz e Terra, 1987. Título original: Stato, governo, società. Per uma teoria generale della política. p.10.

77 En Brasil, se consumó en As Ideologias e o Poder em Crise, con traducción de João Ferreira, publicado por la Editora Universidade de Brasília.

78 NORBERTO BOBBIO, As Ideologias e o Poder em Crise, 4a edición, Traducción de João Ferreira, Brasília, Editora Universidade de Brasília, 1995. Título original: Ideologie e il potere in crise, p. 11.

79 NORBERTO BOBBIO, Diário de um século: Autobiografia, Traducción de Daniela Beccaccia Versiani, Rio de Janeiro, Campus, 1998. Título original: Autobiografia. p. 237. 
PASOLD, Cesar Luiz. El Taedium Vitae De Norberto Bobbio Y La Ética Médica. Revista Eletrônica Direito e Política, Programa de Pós-Graduação Stricto Sensu em Ciência Jurídica da UNIVALI, Itajaí, v.11, n.1, $1^{0}$ quadrimestre de 2016. Disponível em: www.univali.br/direitoepolitica - ISSN 1980-7791.

setenta años, después de cuarenta años de docencia" ${ }^{\prime 80}$. Aún en 1979 se publica en Italia su libro "El problema de la guerra y los caminos de la paz" 81 con el cual Bobbio se destacó en Europa como "prominente y lúcido defensor de una activa consciencia pacifista"${ }^{82}$.

Aun sin ejercer más el magisterio, la vida intelectual de Bobbio permanece activa. Por ejemplo, en 1980, en el mes de octubre, en Castelgandolfo, tiene lugar el Congreso "Max Weber y el Derecho", en el cual Bobbio presentó un trabajo denominado "Max Weber y Hans Kelsen"83. Otro ejemplo: en 1981, en Roma, se realizó un Seminario sobre el Concepto de Izquierda, evento que Bobbio adjetivó como muy importante porque lo consideró como el marco histórico de la "toma de consciencia de la necesidad de comenzar a discutir la razón y el significado de la izquierda, incluso por personas alineadas a la izquierda[... $]^{\prime \prime 84} ;$ y en noviembre de ese mismo año participó en Milán en el segundo seminario internacional dedicado a Gaetano Mosca y con el título Governo e governabilità nel sistema político e giuridico di G. Mosca ${ }^{85}$; la Amnesty International promovió un congreso sobre La pena di morte nel

80 NORBERTO BOBBIO, Diário de um século: Autobiografia, Traducción de Daniela Beccaccia Versiani, Rio de Janeiro, Campus, 1998. Título original: Autobiografia. p. 161.

${ }^{81}$ La edición brasileña llegó solamente en 2003: NORBERTO BOBBIO, O problema da guerra e as vias da paz, Traducción de Álvaro Lorencini, São Paulo, Editora UNESP, 2003. Título original: Il problema della guerra e le vie della pace.

82 Conforme CELSO LAFER, "Guerra, Direito e poder no Golfo Pérsico" En CARDIN, Carlos Henrique (org.), Bobbio no Brasil - um retrato intelectual, Brasília, Editora Universidade de Brasília; São Paulo, Imprensa Oficial do Estado, 2001, p.90.

${ }^{83}$ Vea el texto en portugués en: NORBERTO BOBBIO, (org. José Fernández Santillán). Norberto Bobbio: o filósofo e a política, Traducción de Cesar Benjamin e Vera Ribeiro, Rio de Janeiro, Contraponto, 2003. Título original: Norberto Bobbio: el filosofo y la politica. p. 117 a 134.

${ }^{84}$ NORBERTO BOBBIO, "Prefácio à Primeira Edição Italiana". En BOBBIO, Norberto, Direita e esquerda: razões e significados de uma distinção política, Traducción de Marco Aurélio Nogueira, 2a edición, São Paulo, Unesp, 2001. Título original: Destra e sinistra: ragioni e significati di uma distinzione politica. Nuova edizione riveduta e ampliata com uma risposta ai critici, p. 28, nota de pie de página nº 2.

${ }^{85}$ NORBERTO BOBBIO, Ensaios sobre ciência política na Itália, Traducción de Maria Celeste F. Faria Marcondes, Brasília, Editora Universidade de Brasília- São Paulo, Imprensa Oficial do Estado, 2001. Título original: Saggi sulla scienza política in Italia. p.7, nota de pie de página n०1. 
PASOLD, Cesar Luiz. El Taedium Vitae De Norberto Bobbio Y La Ética Médica. Revista Eletrônica Direito e Política, Programa de Pós-Graduação Stricto Sensu em Ciência Jurídica da UNIVALI, Itajaí, v.11, n.1, $1^{0}$ quadrimestre de 2016. Disponível em: www.univali.br/direitoepolitica - ISSN 1980-7791.

mondo, y Bobbio pronunció la conferencia de abertura, en $1982^{86}$; ese mismo año, en septiembre, estuvo en Brasil acompañado por su esposa y por su cuñada, y pronunció dos conferencias en la Facultad de Derecho de la USP ${ }^{87}$, y en Brasilia participó en la serie "Encontros da UnB" ${ }^{\prime \prime 88}$. Cabe destacar que en Milán, el día 8 de marzo de 1983, Bobbio pronunció una conferencia en el seminario destinado a componer un "Pequeño Diccionario de las Virtudes", con el apoyo de la Fundación Corrente y promovido por Ernesto Treccani. La virtud por él escogida fue la serenidad (mitezza), sobre la cual discurrió con el título "Elogio a la serenidad". El texto básico de esta conferencia se transformó en una de las más elogiadas y debatidas producciones intelectuales de Bobbio, con traducciones al inglés, francés, español y portugués. En este último caso, fue el ensayo que inicia el volumen de la obra "Elogio de la Serenidad y otros ensayos morales"89. El 18 de octubre de 1983 fue al Convento di San Domenico, en Bolonia, y allí pronunció una conferencia con el título "Pros y contras de una ética laica"90. Del 14 al 17 de noviembre de 1983 se celebró en

${ }^{86}$ PIETRO POLITO (org.), "Notas biográficas" En BOBBIO, Norberto, 0 tempo da memória. De senectute e outros escritos autobiográficos, Traducción Daniela Versiani, Rio de Janeiro, Campus, 1997. Título original: De senectute. p. 195.

87 CELSO LAFER, "Prefácio à Edição Brasileira- A Autoridade de Norberto Bobbio" En BOBBIO, Norberto, $\mathbf{O}$ tempo da memória. De senectute e outros escritos autobiográficos, Traducción Daniela Versiani, Rio de Janeiro, Campus, 1997. Título original: De senectute. p.XXV. Con todo, en CARLOS HENRIQUE CARDIN (org.), Bobbio no Brasil - um retrato intelectual, Brasília, Editora Universidade de Brasília; São Paulo, Imprensa Oficial do Estado, 2001. Título original: Autobiografia, p.7 esta visita de Bobbio a Brasil está registrada como ocurrida en 1983.

${ }^{88}$ Informa Carlos Henrique CARDIN que "atendieron a la invitación para debatir sus obras con académicos nacionales y para presentar sus autobiografías, entre otros, Raymond Aron, Gilberto Freyre, John Kenneth Galbraith, René Dubos, Mario Vargas Llosa, Afonso Arinos de Mello Franco, Ernest Gellner, Leszek Kolakowski y Miguel Reale", además de Norberto Bobbio. Conforme CARDIN, Carlos Henrique. Apresentação. In CARLOS HENRIQUE CARDIN (org.), Bobbio no Brasil - um retrato intelectual, Brasília, Editora Universidade de Brasília; São Paulo, Imprensa Oficial do Estado, 2001. Título original: Autobiografia, p.7. Vide también la p. 114.

${ }^{89}$ Ver NORBERTO BOBBIO, Elogio da serenidade e outros ensaios morais, Traducción de Marco Aurélio Nogueira, São Paulo, Editora UNESP, 2002. Título original: Elogio della mitezza e altri scritti morali. p. 206. El texto íntegro en português se encuentra en esta obra antes citada de la p. 29 a 99. El origen de este ensayo está igualmente registrado y su texto completo publicado en francés, en NORBERTO BOBBIO, Le sage et la politique - Écrits Moraux sur la vieillesse et la douceur, Traduit de l'italien par Pierre-Emmanuel Dauzat et Denis Trierweiler, Paris, Édicion Albin Michele, 2004. p. 67 a 98.

90 NORBERTO BOBBIO, Elogio da serenidade e outros ensaios morais, Traducción de Marco Aurélio Nogueira, São Paulo, Editora UNESP, 2002. Título original: Elogio della mitezza e altri 
PASOLD, Cesar Luiz. El Taedium Vitae De Norberto Bobbio Y La Ética Médica. Revista Eletrônica Direito e Política, Programa de Pós-Graduação Stricto Sensu em Ciência Jurídica da UNIVALI, Itajaí, v.11, n.1, $1^{0}$ quadrimestre de 2016. Disponível em: www.univali.br/direitoepolitica - ISSN 1980-7791.

Roma el Congreso Internacional sobre Marx, patrocinado por el Instituto Gramsci, en el cual Bobbio presentó un trabajo intitulado Marx, lo stato e $i$ classici $^{11}$. En noviembre de 1983 pronunció una conferencia en el Palacio de las Cortes, en Madrid, por invitación de su Presidente, el Profesor Gregorio PecesBarba, con el título "El futuro de la democracia"92. Y en 1983 fue publicado en Italia el fruto de un proyecto muy ambicioso, que resultó exitoso, del cual Bobbio fue uno de los tres organizadores (juntamente con Nicola Matteucci y Gianfranco Pasquino): el Dizionario di política ${ }^{93}$. En esta obra, además de coorganizador, Bobbio es el autor de quince entradas. Otro momento de especial destaque: el 18 de julio de 1984 el entonces Presidente da República Italiana, Sandro Pertini, con base en el artículo 59 de la Constitución Italiana, nombró a Norberto Bobbio Senador Vitalicio (senatore a vita), "por los altísimos méritos en el campo social, científico, artístico y literario" ${ }^{\prime 4}$. Y en aquel año, en el que conmemoraba 75 años de vida, una decisión unánime del Colegiado de la Facultad de Ciencias Políticas de Turín le otorgó el título de Profesor Emérito. $Y$ "el 18 de octubre, el mismo Consejo festeja sus cincuenta años de actividades científicas y su $75^{\circ}$ cumpleaños". En esta ocasión fue presentado el volumen Norberto Bobbio: 50 anni di studi. Bibliografia degli scritti 1934-1983, organizado por Carlo Violi", que Bobbio clasificó como "una

scritti morali, p. 208. Un texto adaptado de esta conferencia se encuentra en NORBERTO BOBBIO, (org. José Fernández Santillán). Norberto Bobbio: o filósofo e a política, Traducción de Cesar Benjamin e Vera Ribeiro, Rio de Janeiro, Contraponto, 2003. Título original: Norberto Bobbio: el filosofo y la politica. p. 179 a 191.

${ }^{91}$ El texto en portugués, con el título "Marx, o Estado e os clássicos" se encuentra en NORBERTO BOBBIO, (org. José Fernández Santillán). Norberto Bobbio: o filósofo e a política, Traducción de Cesar Benjamin e Vera Ribeiro, Rio de Janeiro, Contraponto, 2003. Título original: Norberto Bobbio: el filosofo y la politica. p. 77 a 116.

92 Conforme nORBerto BOBbio, O Futuro da Democracia. Uma defesa das regras do jogo, Traducción de Marco Aurélio Nogueira, Rio de Janeiro, Paz e Terra, 1986. Título original: Il futuro della democrazia. Uma difesa delle regole del gioco. p.10.

93 En Brasil: NORBERTO BOBBIO; NICOLA MATTEUCCI; GIANFRANCO PASQUINO, Dicionário de política, Traducción de Carmen C. Varriale et all, 12a edición, Brasília, Editora Universidade Brasília, 2004. II Vol. Título original: Dizzionario di politica.

94 PIETRO POLITO (org.), "Notas biográficas" En BOBBIO, Norberto, 0 tempo da memória. De senectute e outros escritos autobiográficos, Traducción Daniela Versiani, Rio de Janeiro, Campus, 1997. Título original: De senectute. p. 195. 
PASOLD, Cesar Luiz. El Taedium Vitae De Norberto Bobbio Y La Ética Médica. Revista Eletrônica Direito e Política, Programa de Pós-Graduação Stricto Sensu em Ciência Jurídica da UNIVALI, Itajaí, v.11, n.1, $1^{0}$ quadrimestre de 2016. Disponível em: www.univali.br/direitoepolitica - ISSN 1980-7791.

admirable bibliografía", por la metodología utilizada, ya que no le "cabía juzgar" ${ }^{\prime 95}$ el contenido. Del 18 al 20 de octubre de 1984, fue realizado en la ciudad de Turín el congreso denominado Per uma teoria generale della política, dedicado a "su pensamiento y a su obra"96. El 16 de marzo de 1989, Bobbio recibió el premio internacional de la Société Européenne de Culture, en reconocimiento por su "contribución en la promoción de la solidaridad entre los hombres y los pueblos a través de la política y de la cultura". El día de su octogésimo aniversario, el 18 de octubre de 1989, el libro de Bobbio con sus ensayos sobre Thomas Hobbes, editado por la Einaudi, fue presentado en el Aula Magna de la Universidad de Turín ${ }^{97}$. En aquella ocasión Bobbio pronunció un discurso intitulado "Reflexiones de un Octogenario". ${ }^{98}$.

En 1990 fue lanzada la Bibliografia degli scritti di Norberto Bobbio, 1934-1993, una vez más organizada por Carlo Violi ${ }^{99}$. Del 20 al 24 de julio de 1992, la Universidad Internacional Menéndez y Pelayo promovió una jornada de estudios sobre "La figura y el pensamiento de Norberto Bobbio" en el Palacio de Magdalena, en Santander. Allí, en la jornada de clausura, Bobbio hizo un pronunciamiento intitulado "Autobiografía intelectual"100. El 6 de junio, Bobbio

\footnotetext{
95 NORBERTO BOBBIO, O tempo da memória. De senectute e outros escritos autobiográficos, Traducción Daniela Versiani, Rio de Janeiro, Campus, 1997. Título original: De senectute. p. 162. Vide también CARLO VIOLI (org.), Bibliografia degli scritti di Norberto Bobbio. 1934-1993, Roma, Gius.Laterza \& Figli, 1995, p. XXXIX, nota de pie de página nº 5.

96 PIETRO POLITO (org.), "Notas biográficas" En BOBBIO, Norberto, O tempo da memória. De senectute e outros escritos autobiográficos, Traducción Daniela Versiani, Rio de Janeiro, Campus, 1997. Título original: De senectute. p. 196.
}

97 PIETRO POLITO (org.), "Notas biográficas" En BOBBIO, Norberto, O tempo da memória. De senectute e outros escritos autobiográficos, Traducción Daniela Versiani, Rio de Janeiro, Campus, 1997. Título original: De senectute. p. 196.

${ }^{98}$ El texto completo en portugués está en: NORBERTO BOBBIO, O tempo da memória. De senectute e outros escritos autobiográficos, Traducción Daniela Versiani, Rio de Janeiro, Campus, 1997. Título original: De senectute. p. 116 a 121.

99 Ver CARLO VIOLI (org.), Bibliografia degli scritti di Norberto Bobbio. 1934-1993, Roma, Gius.Laterza \& Figli, 1995, p. XL, nota de pie de página 6.

100 El texto completo en portugués está en: NORBERTO BOBBIO, O tempo da memória. De senectute e outros escritos autobiográficos, Traducción Daniela Versiani, Rio de Janeiro, Campus, 1997. Título original: De senectute. p. 122 a 141. 
PASOLD, Cesar Luiz. El Taedium Vitae De Norberto Bobbio Y La Ética Médica. Revista Eletrônica Direito e Política, Programa de Pós-Graduação Stricto Sensu em Ciência Jurídica da UNIVALI, Itajaí, v.11, n.1, $1^{0}$ quadrimestre de 2016. Disponível em: www.univali.br/direitoepolitica - ISSN 1980-7791.

recibió el diploma honoris causa de la Universidad Autónoma de Madrid ${ }^{101}$. El 19 de octubre de 1996, fecha de su $87^{\circ}$ cumpleaños, tuvo lugar en la sede de la Giulio Einaudi Editore, o lanzamiento de De senectute, "il suo ultimo

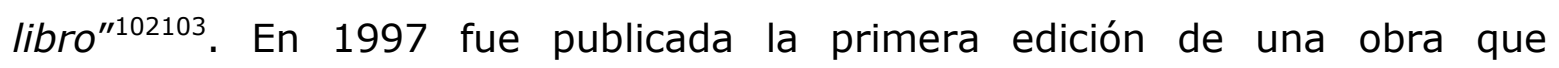
coleccionó ensayos importantes de Bobbio, "a cura de Michelangelo Bovero", intitulada Del Fascismo alla democrazi. ${ }^{104}$ De agosto a diciembre de 2000, Bobbio mantuvo un diálogo intenso con Maurizio Viroli, que fue transformado en texto y que fue revisado por ambos "innumerables veces", transformándose en el libro Dialogo intorno allá Republica. ${ }^{105}$. Y utilizando la expresión de Pietro Rossi, conforme ya había sido informado al principio del presente artículo, la morte lo há colto il 9 gennaio $2004^{106}$.

\section{El Taedium Vitae de Norberto Bobbio y la ética de la decisión de su hijo, el médico Marco Bobbio}

Aun habiendo sido relatada resumidamente la vida profesional de Norberto Bobbio, queda evidenciada la riqueza intelectual y científica de su vida, que a partir de determinado momento, por los efectos de la edad avanzada, se ve entorpecida, radicalmente disminuida, dejándolo inactivo y sin producción.

101 El discurso de Bobbio, con el nombre de "Um balanço", está en: NORBERTO BOBBIO, O tempo da memória. De senectute e outros escritos autobiográficos, Traducción Daniela Versiani, Rio de Janeiro, Campus, 1997. Título original: De senectute. p. 162 a 173.

102 En traducción libre al portugués del autor de este texto: su último libro. Conforme el registro PIETRO ROSSI, "Introduzione" En ZAGREBESLKY, Gustavo; et ali, Norberto Bobbio tra diritto e política, Roma, Editori Laterza, 2005. p. XVI.

103 NORBERTO BOBBIO, O tempo da memória. De senectute e outros escritos autobiográficos, Traducción Daniela Versiani, Rio de Janeiro, Campus, 1997. Título original: De senectute.

104 NORBERTO BOBBIO, Dal fascismo ala democrazia, I regimi, le ideologie, le figure e la cultura politiche, (A Cura de Michelangelo Bovero), Milano, Baldino\&Castoldi, 1997. Esta obra volvió a tener ediciones póstumas en 2008 y en 2014.

105 MAURIZIO VIROLI, "Prefácio", En BOBBIO, Norberto; VIROLI, Maurizio Diálogo em torno da República: os grandes temas da política e da cidadania, Traducción de Daniela Beccaccia Versiani, Rio de Janeiro: Campus, 2002. Título original: Diálogo intorno alla republica p. 7.

106 PIETRO ROSSI, "Introduzione" En ZAGREBESLKY, Gustavo; et ali, Norberto Bobbio tra diritto e política, Roma, Editori Laterza, 2005. p. V. 
PASOLD, Cesar Luiz. El Taedium Vitae De Norberto Bobbio Y La Ética Médica. Revista Eletrônica Direito e Política, Programa de Pós-Graduação Stricto Sensu em Ciência Jurídica da UNIVALI, Itajaí, v.11, n.1, 10 quadrimestre de 2016. Disponível em: www.univali.br/direitoepolitica - ISSN 1980-7791.

Por eso es comprensible que Bobbio, en estas condiciones por al menos cuatro años sucesivos, haya sentido tedio, desánimo y desmotivación para vivir. No tomó ninguna providencia para interrumpir su existencia, pero verbalizó la insatisfacción de que estaba tomado para los familiares, en especial para los hijos. En octubre de 2003 completó los 94 años de vida. Dos meses después, el 27 de diciembre, sufrió una neumonía y fue sometido a internación hospitalaria, considerada su dificultad para respirar. Mejoró de este mal y retornó a su casa. Sin embargo, en poco tiempo su estado se agravó, y en cumplimiento de la decisión de su hijo Marco Bobbio, médico cardiólogo, fue dispensado deliberadamente de cualquier tratamiento para prolongar la vida, así como tampoco fue adoptada ninguna medida medicamentosa que abreviase la llegada de su muerte, cuidando, con todo, de proporcionar "soporte médico para controlar el malestar causado por la enfermedad"107. Bobbio falleció el 9 de enero de 2004.

Esta conducta resultante de la decisión del médico Marco Bobbio, hijo del paciente, ¿merece sufrir crítica o restricción desde la perspectiva de una Ética General? ¿Y bajo la mirada de una Ética específicamente Médica?

En lo que concierne a la Ética General (y aquí no se cuida de la Moral, conforme distintos conceptos operacionales propuestos en el inicio de este artículo), la indagación podría contemplar el aspecto específico resultante del hecho de que la decisión de la conducta tuvo origen en uno de los tres hijos del paciente, en este caso del hijo de profesión médico. Esta condición, debe ser destacado, lo calificaba mejor para este tipo de decisión desde el punto de vista clínico y médico. No se tuvo acceso a la información sobre si Marco Bobbio consultó o no a sus otros dos hermanos ${ }^{108}$. Si lo hizo, debe de haber obtenido el apoyo para la opción que acabó por ser efectuada. Y en este contexto no hay ningún perjuicio a la Ética General, porque la medida

107 Conforme MARCO BOBBIO, Moderação e Serenidade, Entrevista para Adriana Dias Lopes, revista Veja-edição 2402, ano 47, n49, 03/12/2014, p.21.

${ }^{108}$ La esposa de Bobbio ya había fallecido y obviamente no había cómo consultarla. 
PASOLD, Cesar Luiz. El Taedium Vitae De Norberto Bobbio Y La Ética Médica. Revista Eletrônica Direito e Política, Programa de Pós-Graduação Stricto Sensu em Ciência Jurídica da UNIVALI, Itajaí, v.11, n.1, $1^{0}$ quadrimestre de 2016. Disponível em: www.univali.br/direitoepolitica - ISSN 1980-7791.

adoptada respetó la Dignidad Humana de Norberto Bobbio, respetando su vida, su voluntad verbalizada de forma indirecta, y su muerte. Pero es conveniente considerar la segunda hipótesis situacional, aquella que trae la posibilidad de que Marco no consultó a sus dos hermanos. $Y$ a partir de tal referente se puede inferir que tomó el camino dictado por su condición de hijo que amaba a su padre, y principalmente por su consciencia de médico.

Desde tal perspectiva, en la que la formación profesional se hace muy presente, se puede llevar la cuestión al campo de la Ética Médica, y en él objetivamente verificar como ella - la situación -, y no él - Marco Bobbio -, se encuadra.

Considerando el "Código de Deontología Médica" de Italia ${ }^{109}$, centramos la atención en su artículo 16, cuya transcripción literal se hace necesaria, porque el tenor es claro y didáctico para apreciación de la aplicación o no al caso concreto. Así:

Artículo 16: Obstinación diagnóstico-terapéutica.

El médico, tomando en consideración la voluntad del paciente cuando expresa, debe abstenerse de la obstinación en el tratamiento diagnóstico y terapéutico, en las situaciones en las que no se puede fundamentalmente beneficiar la salud del enfermo y/o mejora de la calidad de vida" ${ }^{110}$.

Merece destaque, asimismo, dentro del Capítulo V intitulado "Asistencia a los Enfermos Incurables", el artículo 39, que dispone:

Art. 39: Asistencia al enfermo con pronóstico infausto. En caso de enfermedades o pronósticos seguramente

${ }^{109}$ Este Código fue aprobado el 10 de diciembre de 2006, por lo tanto dos años después de la muerte de Bobbio. Para los efectos del ejercicio efectuado en el presente artículo, es válido en la medida en que su explicitación es compatible con la línea de análisis aquí adoptada, es decir, no se busca "encuadrar o no a Marco Bobbio" sino, objetivamente, verificar la situación frente a ciertas normas éticas, seleccionadas a título ejemplificativo.

${ }^{110}$ Conforme consta en el excelente artículo: LEO PESSINI, Códigos de ética e questões de final de vida: Uma leitura ética comparada, En: http://www.portalmedico.org.br/novocodigo/artigo2.htm. Acceso en 08/04/2015. 
PASOLD, Cesar Luiz. El Taedium Vitae De Norberto Bobbio Y La Ética Médica. Revista Eletrônica Direito e Política, Programa de Pós-Graduação Stricto Sensu em Ciência Jurídica da UNIVALI, Itajaí, v.11, n.1, $1^{0}$ quadrimestre de 2016. Disponível em: www.univali.br/direitoepolitica - ISSN 1980-7791.

infaustos o surgidos en la fase final, el médico debe, a través de actos y comportamientos idóneos, evitar al enfermo sufrimientos psicofísicos y proporcionar tratamientos apropiados, cuando sea posible, que salvaguarden la calidad de vida y la dignidad de la persona.

En el caso de comprometimiento del estado de consciencia, el médico debe proseguir la terapia de sustento vital hasta cuando se juzgue razonablemente útil, evitando toda forma de obstinación. ${ }^{111}$

Para los efectos del presente artículo, se considera que Norberto Bobbio expresó, aunque se considere como de forma indirecta, su deseo de que la vida no le fuese prolongada artificialmente, porque sentía y verbalizó su Taedium vitae, es decir, su tedio/cansancio de vivir. En esta línea, la decisión de Marco Bobbio estaría protegida por el artículo 16. Por otra parte, Norberto Bobbio tuvo agravado su estado de salud justo después de una mejora de la neumonía, lo que también alberga la conducta de Marco en el artículo 39.

Siguiendo el camino de este razonamiento, la opción de Marco Bobbio puede ser considerada como estando amparada también:

(1) por el "Código Deontológico" de Portugal, en el artículo 49, que se ocupa del "deber de abstención de la terapéutica sin esperanzas", incluido en el Capítulo II; y,

(2) por el "Código de Ética y Deontología Médica" de España, cuyo Capítulo VII está enteramente dedicado a la muerte, y en cuyo artículo 27 , ítem 2, se encuentra que "el médico no deberá iniciar o continuar acciones diagnósticas o terapéuticas sin esperanza, inútiles u obstinadas". ${ }^{112}$

Desde una perspectiva mundial, se destaca ahora el "CÓDIGO INTERNACIONAL

${ }^{111}$ También conforme consta en LEO PESSINI, Códigos de ética e questões de final de vida: Uma leitura ética comparada, En: http://www.portalmedico.org.br/novocodigo/artigo2.htm. Acceso en 08/04/2015.

112 También conforme consta en LEO PESSINI, Códigos de ética e questões de final de vida: Uma leitura ética comparada, En: http://www.portalmedico.org.br/novocodigo/artigo2.htm. Acceso en 08/04/2015. 
PASOLD, Cesar Luiz. El Taedium Vitae De Norberto Bobbio Y La Ética Médica. Revista Eletrônica Direito e Política, Programa de Pós-Graduação Stricto Sensu em Ciência Jurídica da UNIVALI, Itajaí, v.11, n.1, $1^{0}$ quadrimestre de 2016. Disponível em: www.univali.br/direitoepolitica - ISSN 1980-7791.

de ÉTICA MÉDICA"113, que fue inicialmente aprobado por la "3a Asamblea General de la $A M M^{114 \prime \prime}$, realizada en Londres, Inglaterra, en 1949. Fue modificado por la "22a Asamblea Médica Mundial", que tuvo lugar en 1968 en Sídney, Australia, y después por la "35a Asamblea Médica Mundial" realizada en Venecia, Italia, en 1983. En él, entre los "Deberes de los Médicos en general"115, se encuentra literalmente que: "EL MEDICO DEBE, en todos los tipos de práctica médica, dedicarse a proporcionar un servicio médico competente, con plena independencia técnica y moral, con compasión y respeto por la dignidad humana."116

En verdad, lo que este "deber' consagra es el reconocimiento explícito de un Principio de la Ética Médica Mundial, que es el de que en el ejercicio de la Medicina, el profesional debe ser competente, tener independencia técnica y moral (aquí, con la debida venia, la palabra más adecuada sería ética), y tener compasión para con el paciente y respeto por la dignidad humana.

Marco Bobbio, en este episodio y conforme su propio relato, cumplió este Principio/Deber ${ }^{117}$, especialmente en lo que concierne al ejercicio de la compasión (que no se ha de confundir con piedad) para con su padre/paciente (y para con el Taedium vitae de Norberto), y al respeto por la Dignidad Humana. Este respeto, pido perdón por la insistencia, ha de ser practicado en relación a la vida y a la muerte de las personas.

Y el caso examinado en el presente artículo, ¿cómo queda cuando se considera

113 Conforme: ASSOCIAÇÃO MUNDIAL DE MEDICINA, Código Internacional de Ética Médica, En <http://www.wma.net/es/30publications/10policies/c8/17a_es.pdf>. Acceso el 08/04/2015.

114 La sigla AMM significa: Asociación Médica Mundial.

115 "Deveres dos Médicos em geral". (Traducción libre del autor del presente artículo).

116 "O MÉDICO DEVE, em todos os tipos de prática médica, dedicar-se a proporcionar um serviço médico competente, com total independência técnica e moral, tendo compaixão e respeito pela dignidade humana." (Traducción libre del autor del presente artículo).

117 El lector debe ser advertido de que escapa al enfoque del presente artigo discutir los conceptos de Principio, de Derecho y de Deber. En esta frase se conecta la palabra original en el documento examinado ("deber"= dever) con la idea de que el mismo excede la condición de deber y alcanza el nivel de Principio Ético Médico. 
PASOLD, Cesar Luiz. El Taedium Vitae De Norberto Bobbio Y La Ética Médica. Revista Eletrônica Direito e Política, Programa de Pós-Graduação Stricto Sensu em Ciência Jurídica da UNIVALI, Itajaí, v.11, n.1, $1^{0}$ quadrimestre de 2016. Disponível em: www.univali.br/direitoepolitica - ISSN 1980-7791.

el Código de Ética Médica vigente en Brasil ${ }^{118}$

Aprobado por la RESOLUCIÓN CFM No 1931/2009, que fue publicada en el D.O.U. del 24 de setiembre de 2009, Sección I, p. 90, y con rectificación publicada en el D.O.U. del 13 de octubre de 2009, Sección I, p.173, entró en vigor en Brasil el nuevo Código de Ética Médica el 13 de abril de $2010^{119}$.

Su forma y contenido están legitimados, porque el Código resultó de decisiones aprobadas por la IV Conferencia Nacional de Ética Médica, y su elaboración es consecuencia de la "participación de Delegados Médicos de todo el Brasil". Posee algunas características muy interesantes que merecen ser mencionadas. La primera es una de las directrices generales en la cual se encuentra explícito que el Código está compuesto por reglas que van mucho más allá de la estricta disciplina del ejercicio de la profesión médica, alcanzando a todas las actividades en las que son utilizados conocimientos provenientes de la Medicina. Estructuralmente está integrado por "25 principios fundamentales del ejercicio de la Medicina, 10 normas diceológicas, 118 normas deontológicas y cuatro disposiciones generales".

Se destacan algunos principios:

(1) el que consta en el inciso XXII, cuyo tenor es: "En las situaciones clínicas irreversibles y terminales, el médico evitará la realización de procedimientos diagnósticos y terapéuticos innecesarios y propiciará a los pacientes bajo su atención todos los cuidados paliativos apropiados.";

(2) el sexto principio, que establece que el médico tendrá respeto absoluto por el ser humano y actuará siempre en

118 Aquí fueron considerados, concentrando y seleccionando específicamente en relación a la conducta de Marco Bobbio, los textos: CESAR LUIZ PASOLD, O novo Código de Ética Médica: primeira aproximação descritiva, En http://www.advocaciapasold.com.br/publicacoes/artigos.php. Acceso el 8 de abril de 2015. y, CESAR LUIZ PASOLD, A Principiologia do novo Código de Ética Médica. En: http://www.advocaciapasold.com.br/publicacoes/artigos.php. Acceso el 8 de abril de 2015.

119 Todas las citas y transcripciones literales que siguen tienen como fuente: CONSELHO FEDERAL DE MEDICINA, Resolução CFM No 1931/2009-Institui o Código de Ética Médica. Em: http://www.portalmedico.org.br/resolucoes/CFM/2009/1931_2009.htm. Acceso el 11 de abril de 2015. 
PASOLD, Cesar Luiz. El Taedium Vitae De Norberto Bobbio Y La Ética Médica. Revista Eletrônica Direito e Política, Programa de Pós-Graduação Stricto Sensu em Ciência Jurídica da UNIVALI, Itajaí, v.11, n.1, $1^{0}$ quadrimestre de 2016. Disponível em: www.univali.br/direitoepolitica - ISSN 1980-7791.

su beneficio; de esto se desprende que al médico le está vedado utilizar sus conocimientos en una triple dimensión negativa: a) para causar sufrimiento físico o moral; b) para el exterminio del ser humano; y c) para permitir y encubrir tentativa contra su dignidad e integridad;

(3) el vigésimo primer Principio, que se ocupa del relevante aspecto relacionado al proceso de toma de decisiones profesionales, en el cual "de acuerdo con sus dictámenes de consciencia y las previsiones legales, el médico aceptará las elecciones de sus pacientes, relativas a los procedimientos diagnósticos y terapéuticos por ellos expresados, siempre que sean adecuadas al caso y científicamente reconocidas";

(4) el vigésimo segundo Principio, que trata de las situaciones clínicas irreversibles y terminales, en las cuales "el médico evitará la realización de procedimientos diagnósticos y terapéuticos innecesarios y propiciará a los pacientes bajo su atención todos los cuidados paliativos apropiados."

Y se destaca también el siguiente trecho estratégico del artículo 23: "Le está vedado al médico:" [...] "Tratar al ser humano sin civilidad o consideración, no respetar su dignidad o discriminarlo de cualquier manera o bajo cualquier pretexto".

Corresponde al sexto Principio antes destacado y cuyo entero tenor es:

VI - El médico guardará absoluto respeto por el ser humano y actuará siempre en su beneficio. Jamás utilizará sus conocimientos para causar sufrimiento físico o moral, para el exterminio del ser humano o para permitir y encubrir tentativa contra su dignidad e integridad."

Marco Bobbio procedió, es preciso repetir, respetando la dignidad de su padre Norberto, en conducta compatible con el espíritu y el núcleo de la letra del antes citado artículo 23.

En lo que concierne a los cuatro principios del Código de Ética Médica de Brasil, antes seleccionados y destacados, hay que hacer hincapié en que el médico Marco Bobbio: 
PASOLD, Cesar Luiz. El Taedium Vitae De Norberto Bobbio Y La Ética Médica. Revista Eletrônica Direito e Política, Programa de Pós-Graduação Stricto Sensu em Ciência Jurídica da UNIVALI, Itajaí, v.11, n.1, $1^{0}$ quadrimestre de 2016. Disponível em: www.univali.br/direitoepolitica - ISSN 1980-7791.

(1) no sometió al paciente a procedimientos diagnósticos y terapéuticos innecesarios, y se preocupó para que Norberto no sufriese;

(2) procedió en absoluto respeto al ser humano Norberto Bobbio evitándole sufrimiento físico o mental;

(3) en su proceso de toma de decisión profesional, el médico Marco Bobbio consideró firmemente la información privilegiada que tenía como hijo de Norberto, quien había verbalizado insistentemente su taedium vitae;

(4) evitó procedimientos innecesarios, ya sea de diagnóstico o terapéuticos, y proporcionó los cuidados paliativos apropiados al paciente.

Una primera indagación puntual puede ser presentada: ¿La condición de Marco como hijo no plantea ninguna reserva de orden ético a la actuación médica (incluso con decisión estratégica sobre su conducta en relación a la muerte) junto al padre, Norberto, enfermo?

En el examen de los Códigos de Ética seleccionados para sustentar ilustrativamente el presente artículo, este aspecto específico no fue encontrado.

Con todo, la lectura y la reflexión realizadas sobre los dispositivos axiológicos examinados durante la investigación permiten una opinión en el sentido de que la relación familiar (cualquiera sea el grado, que en el caso concreto aquí verificado es muy próximo) entre médico y paciente, en sí, no constituye impeditivo a la actuación del profesional.

Lo que los fundamentos explícitos y algunos implícitos (por lo tanto, en estos la percepción es más subjetiva) encontrados en los Códigos apreciados parecen indicar es que lo más importante a considerar son las actitudes, los comportamientos $^{120}$ del profesional médico, verificándose el nivel de su

120 "Actitud entendida como predisposición o tendencia interna en la Personalidad, se distingue de comportamiento en la medida en que este es comprendido como acción u omisión, en una situación dada". In CESAR LUIZ PASOLD, Personalidade e Comunicação, 2a edición, Florianópolis, Plus Saber Editora, 2005, p.69, nota de pie de página no 36. (Negritos en el 
PASOLD, Cesar Luiz. El Taedium Vitae De Norberto Bobbio Y La Ética Médica. Revista Eletrônica Direito e Política, Programa de Pós-Graduação Stricto Sensu em Ciência Jurídica da UNIVALI, Itajaí, v.11, n.1, 10 quadrimestre de 2016. Disponível em: www.univali.br/direitoepolitica - ISSN 1980-7791.

sostenibilidad axiológica. En este menester, se debe dar atención principalmente a la obediencia al principio del respeto a la Dignidad Humana, al proceso de toma de decisión amparado en la competencia técnica, ya sea la diagnóstica o la terapéutica, y en los valores de la adecuada práctica de la Medicina.

Y la segunda indagación puntual, para concluir: al relatar el hecho en una entrevista publicada en una revista de circulación nacional en Brasil, Marco Bobbio, independientemente de su nacionalidad, ¿quebró la regla ética del sigilo profesional?

Desde el punto de vista del Código Brasileño que se enfatiza en el presente artículo, se trae a colación el tenor del art. 73:

revelar hecho de que tenga conocimiento en virtud del ejercicio de su profesión, salvo por motivo justo, deber legal o consentimiento, por escrito, del paciente. Párrafo único. Permanece esa prohibición: a) aunque el hecho sea de conocimiento público o el paciente haya fallecido; $[. .$.$] .$

En ese momento, ¿la condição de médico y concomitantemente de hijo del paciente, agrava o atenúa?

¿O no hay violación del sigilo profesional, porque existe motivo justo, que sería el de sustentar sólidamente la defensa pública de la aplicación del principio ético del respeto a la Dignidad Humana (en la vida y en la muerte) del paciente?

iEstas últimas indagaciones permanecen también como especiales estímulos a la reflexión de los lectores!

CONSIDERACIONES FINALES

original). 
PASOLD, Cesar Luiz. El Taedium Vitae De Norberto Bobbio Y La Ética Médica. Revista Eletrônica Direito e Política, Programa de Pós-Graduação Stricto Sensu em Ciência Jurídica da UNIVALI, Itajaí, v.11, n.1, $1^{0}$ quadrimestre de 2016. Disponível em: www.univali.br/direitoepolitica - ISSN 1980-7791.

En este artículo se intentó realizar un proceso reflexivo, desde el punto de vista axiológico, sobre el hecho de Marco Bobbio, médico cardiólogo italiano, haber decidido no aplicar ningún tratamiento de prolongamiento de vida a su padre, el Filósofo, Científico y Jurista Norberto Bobbio, cuando este sufrió reinternación hospitalaria en estado grave, a los 94 años de edad, falleciendo poco después.

El principal argumento del médico es que Norberto venía verbalizando a los familiares un Taedium Vitae.

Tal sentimiento puede ser considerado como plenamente justificable, porque la vida del mismo - Norberto Bobbio -, como se ejemplificó en el ítem anterior del presente artículo, fue extensa y muy productiva, siendo él mismo el originador de estímulos significativos, relevantes y de excelencia cualitativa en diversos campos del conocimiento humano.

Su influencia epistemológica ocurrió especialmente en la Filosofía, en la Filosofía del Derecho, en la Ciencia Política, en la Teoría Política, en la Filosofía Política y en la Teoría General del Derecho y del Estado.

Para fundamentar ilustrativamente tal reflexión se examinaron cinco Códigos de Ética, incluyendo el que actualmente está en vigor en Brasil, este con mayor énfasis. ${ }^{121}$

La conclusión, consideradas las disposiciones deontológicas seleccionadas, fue la de que el médico Marco Bobbio procedió en el episodio sin daño ético.

Al preparar el final de este artículo, se analizó objetivamente el aspecto de la relación familiar (muy cercana, en este caso) del médico Marco como hijo del paciente Norberto y tomando en consideración que la actuación de Marco como profesional no sufre reservas por ser hijo del paciente, no se identifica problema ético.

121 Códigos de Italia, Portugal, España, Brasil y Código Internacional de Ética, conforme referenciado en los pies de página pertinentes, antes citados. 
PASOLD, Cesar Luiz. El Taedium Vitae De Norberto Bobbio Y La Ética Médica. Revista Eletrônica Direito e Política, Programa de Pós-Graduação Stricto Sensu em Ciência Jurídica da UNIVALI, Itajaí, v.11, n.1, $1^{0}$ quadrimestre de 2016. Disponível em: www.univali.br/direitoepolitica - ISSN 1980-7791.

Incluso se deja una indagación especial a los lectores en cuanto a la infracción o no de Marco Bobbio a la regla ética del sigilo profesional cuando hizo pública su conducta y la situación de la muerte de Norberto Bobbio, en una entrevista publicada en una revista brasileña de circulación nacional.

Y por último se registra la esperanza de que este modesto artículo pueda estimular investigaciones, debates y la profundización del tema tratado a partir de un caso real, siempre bajo la égida de la más adecuada relación entre la Vida, la Muerte ${ }^{122}$ y la Dignidad Humana ${ }^{123}$.

\section{REFERENCIAS DE LAS FUENTES CITADAS}

ABBAGnANO, Nicola, Dicionário de Filosofia, Traducción de Alfredo Bosi, São Paulo: Martins Fontes, 1998. Título original: Dizionario di Filosofia.

ALVES, Alaôr Caffé, "Apresentação". en BOBBIO, Norberto, Teoria da norma jurídica, Traducción de Fernando Pavan Baptista e Ariani Bueno Studatti, 20 edición, Bauru, Edipro, 2003. Título original: Teoria della norma giuridica.

ARISTOTELES, Ética a Nicômacos, Traducción de Mário da Gama Kury, 3a edición, Brasília, Editora Universidade de Brasília,1999. Título original: Ethicon Nikomacheion.

ARISTÓTELES, Arte Retórica e Arte Poética, Traducción de Antonio Pinto de Carvalho, Rio de Janeiro, Tecnoprint, s/d, Título original: Art Rhétorique et Art Poétique.

ASSOCIAÇÃO MUNDIAL DE MEDICINA, Código Internacional de Ética Médica, <http://www.wma.net/es/30publications/10policies/c8/17a_es.pdf>. Acceso el 08/04/2015.

BOBBIO, Marco, Moderação e Serenidade, Entrevista para Adriana Dias Lopes, revista Veja-edição 2402, ano 47, n049, 03/12/2014, p.17a 22.

122 Con referencia al derecho a una muerte digna, ver noticiario sobre propuesta, en Francia, de derecho a la muerte con dignidad, en: DANIEL MENEZES, França propõe a sedação terminal para uma morte digna, En http://www.opotiguar.com.br/franca-propoe-a-sedacao-terminalpara-uma-morte-digna/. Acceso el 12 de abril de 2015.

${ }^{123}$ Esta tríada es tema con estrecha conexión con la cuestión del Testamento Vital. Sobre el asunto, vide: LUCIANA DADALTO PENALVA, As contribuições da Experiência Estrangeira para o debate acerca da Legitimidade do Testamento Vital no Ordenamento Jurídico Brasileiro, En: http://www.advocaciapasold.com.br/artigos/arquivos/testamento_vital_contribuicao.pdf. Acceso el 8 abril de 2015. 
PASOLD, Cesar Luiz. El Taedium Vitae De Norberto Bobbio Y La Ética Médica. Revista Eletrônica Direito e Política, Programa de Pós-Graduação Stricto Sensu em Ciência Jurídica da UNIVALI, Itajaí, v.11, n.1, $1^{0}$ quadrimestre de 2016. Disponível em: www.univali.br/direitoepolitica - ISSN 1980-7791.

BOBBIO, Norberto, Diário de um século: Autobiografia, Traducción de Daniela Beccaccia Versiani, Rio de Janeiro, Campus, 1998. Título original: Autobiografia.

BOBBIO, Norberto, "Prefazione". en VIOLI, Carlo (org.). Bibliografia degli scritti di Norberto Bobbio. 1934-199,. Roma, Gius.Laterza \& Figli, 1995.

BOBBIO, Norberto, 0 tempo da memória. De senectute e outros escritos autobiográficos, Traducción Daniela Versiani, Rio de Janeiro, Campus, 1997. Título original: De senectute.

BOBBIO, Norberto, "Premissa". en BOBBIO, Norberto, Thomas Hobbes, Traducción de Carlos Nélson Coutinho, Rio de Janeiro, Campus, 1991. Título original: Thomas Hobbes.

BOBBIO, Norberto, Perfil ideologico del siglo XX en Italia, Traducción para o español de Stella Mastrangelo, México-DF, Fondo de Cultura Económica, 1993. Título original: Profilo ideologico del Novecento italiano.

BOBBIO, Norberto, "Prefácio à primeira edição italiana". en BOBBIO, Norberto, O problema da guerra e as vias da paz, Traducción de Álvaro Lorencini São Paulo Editora UNESP, 2003. Título original: Il problema della guerra e le vie della pace.

BOBBIO, Norberto, Entre duas Repúblicas: as origens da democracia italiana, Traducción de Mabel Malheiros Bellati, São Paulo, Imprensa Oficial do Estado, 2001. Título original: Tra due repubblichi- Alle origini della democrazia italiana.

BOBBIO, Norberto, "Autobiografia Intellettuale". en VIOLI, Carlo (org.). Bibliografia degli scritti di Norberto Bobbio. 1934-1993, Roma, Gius.Laterza \& Figli, 1995.

BOBBIO, Norberto, "Prefácio à segunda edição". en BOBBIO, Norberto, Direito e estado no pensamento de Emanuel Kant, Traducción de Alfredo Fait, Brasília, Editora Universidade de Brasília, 1984. Título original: Diritto e Stato nel Pensiero di Emanuele Kant.

BOBBIO, Norberto, Ensaios sobre Gramsci e o Conceito de Sociedade Civil, Traducción de Marco Aurélio Nogueira e Carlos Nélson Coutinho, São Paulo, Paz e Terra, 1999. Título original: Saggi su Gramsci.

BOBBIO, Norberto, Teoria da norma jurídica, Traducción de Fernando Pavan Baptista e Ariani Bueno Studatti, 2a edición, Bauru, Edipro, 2003, 192 p. Título original: Teoria della norma giuridica.

BOBBIO, Norberto, Teoria do Ordenamento Jurídico, Traducción de Maria Celeste Cordeiro Leite dos Santos. 10a edición, Brasília, Editora Universidade de Brasília, 1999. Título original: Teoria dell' ordinamento giuridico. 
PASOLD, Cesar Luiz. El Taedium Vitae De Norberto Bobbio Y La Ética Médica. Revista Eletrônica Direito e Política, Programa de Pós-Graduação Stricto Sensu em Ciência Jurídica da UNIVALI, Itajaí, v.11, n.1, $1^{0}$ quadrimestre de 2016. Disponível em: www.univali.br/direitoepolitica - ISSN 1980-7791.

BOBBIO, Norberto, "Prefácio à Nova Edição". en BOBBIO, Norberto, $\mathbf{O}$ positivismo jurídico: lições de Filosofia do Direito, Traducción de Márcio Pugliesi et ali, São Paulo, Icone, 1995.

BOBBIO, Norberto, Contribuicion ala teoría del derecho, Traducción para o español de Afonso Ruiz Miguel, Madri, Editorial Debate, 1990.

BOBBIO, Norberto, Elogio da serenidade e outros ensaios morais, Traducción de Marco Aurélio Nogueira, São Paulo, Editora UNESP, 2002. Título original: Elogio della mitezza e altri scritti morali.

BOBBIO, Norberto, "Prefácio à primeira edição italiana". En BOBBIO, Norberto, O problema da guerra e as vias da paz, Traducción de Álvaro Lorencini, São Paulo, Editora UNESP, 2003. Título original: Il problema della guerra e le vie della pace.

BOBBIO, Norberto, "Prefácio para a edição brasileira". en BOBBIO, Norberto, A Teoria das Formas de Governo, Traducción de Sérgio Bath, $2^{a}$ edición, Brasília, Editora Universidade de Brasília, 1980. Título original: La teoria delle forme di governo nella storia del pensiero politico: anno accademico 1975-76.

BOBBIO, Norberto, (org. Michelangelo Bovero) Teoria Geral da Política: a filosofia política e as lições dos clássicos, Traducción de Daniela Beccaccia Versiani, Rio de Janeiro, Campus, 2002. Título original: Teoria Generale della Politica.

BOBBIO, Norberto, A Era dos Direitos, Traducción de Carlos Nélson Coutinho, $5^{a}$ reimpresión, Rio de Janeiro, Campus, 1992. Título original: L' Etàt dei Diritti.

BOBBIO, Norberto, "Premissa". En BOBBIO, Norberto; BOVERO, Michelangelo, Sociedade e Estado na filosofia política moderna, Traducción de Carlos Nelson Coutinho, 3a edición, São Paulo, Brasiliense, 1991. Título original: Società e stato nella filosofia politica moderna.

BOBBIO, Norberto, Ensaios sobre ciência política na Itália, Traducción de Maria Celeste F. Faria Marcondes, Brasília, Editora Universidade de BrasíliaSão Paulo, Imprensa Oficial do Estado, 2001. Título original: Saggi sulla scienza política in Italia.

BOBBIO, Norberto, "Prefácio". En BOBBIO, Norberto, Estado, governo, sociedade; por uma teoria geral da política, Traducción de Marco Aurélio Nogueira, $2^{\text {a }}$ edición, Rio de Janeiro, Paz e Terra, 1987. Título original: Stato, governo, società. Per uma teoria generale della política.

BOBBIO, Norberto, As Ideologias e o Poder em Crise, $4^{a}$ edición, Traducción de João Ferreira, Brasília, Editora Universidade de Brasília, 1995. Título original: Ideologie e il potere in crise.

BOBBIO, Norberto, (org. José Fernández Santillán). Norberto Bobbio: o filósofo e a política, Traducción de Cesar Benjamin e Vera Ribeiro, Rio de 
PASOLD, Cesar Luiz. El Taedium Vitae De Norberto Bobbio Y La Ética Médica. Revista Eletrônica Direito e Política, Programa de Pós-Graduação Stricto Sensu em Ciência Jurídica da UNIVALI, Itajaí, v.11, n.1, $1^{0}$ quadrimestre de 2016. Disponível em: www.univali.br/direitoepolitica - ISSN 1980-7791.

Janeiro, Contraponto, 2003. Título original: Norberto Bobbio: el filosofo y la politica.

BOBBIO, Norberto, "Prefácio à Primeira Edição Italiana". En BOBBIO, Norberto, Direita e esquerda: razões e significados de uma distinção política, Traducción de Marco Aurélio Nogueira, 2a edición, São Paulo, Unesp, 2001. Título original: Destra e sinistra: ragioni e significati di uma distinzione politica. Nuova edizione riveduta e ampliata com uma risposta ai critici.

BOBBIO, Norberto, Le sage et la politique - Écrits Moraux sur la vieillesse et la douceur, Traduit de l'italien par Pierre-Emmanuel Dauzat et Denis Trierweiler, Paris, Édicion Albin Michele, 2004.

BOBBIO, Norberto, O Futuro da Democracia. Uma defesa das regras do jogo, Traducción de Marco Aurélio Nogueira, Rio de Janeiro, Paz e Terra, 1986. Título original: Il futuro della democrazia. Uma difesa delle regole del gioco.

BOBBIO, Norberto; MATTEUCCI, Nicola; PASQUINO, Gianfranco, Dicionário de política, Traducción de Carmen $C$. Varriale et all, 12a edición, Brasília, Editora Universidade Brasília, 2004. II Vol. Título original: Dizzionario di politica.

BOBBIO, Norberto, Dal fascismo ala democrazia, I regimi, le ideologie, le figure e la cultura politiche, (A Cura de Michelangelo Bovero), Milano, Baldino\&Castoldi, 1997.

BOBBIO, Norberto, 0 problema da guerra e as vias da paz, Traducción de Álvaro Lorencini, São Paulo, Editora UNESP, 2003. Título original: Il problema della guerra e le vie della pace.

CARDIN, Carlos Henrique (org.), Bobbio no Brasil - um retrato intelectual, Brasília, Editora Universidade de Brasília; São Paulo, Imprensa Oficial do Estado, 2001. Título original: Autobiografia.

COMPARATO, Fábio Konder, Ética- Direito, Moral e Religião no Mundo Moderno, $3^{a}$ reimpresión, São Paulo, Companhia das Letras, 2006;

CONSELHO FEDERAL DE MEDICINA, Resolução CFM No 1931/2009-Institui o Código de Ética Médica. Em: http://www.portalmedico.org.br/resolucoes/CFM/2009/1931_2009.htm. Acceso el 11 de abril de 2015.

FIGUEIRA, M. S, "A eticidade no ofício de julgar" Em: Verbis. (12), 1998.

GIANOTTI, José Arthur, "Moralidade Pública e Moralidade Privada" En NOVAES, Adauto (org.), Ética, São Paulo, Companhia das Letras/Secretaria Municipal de Cultura, 1992.

HEGEL, G. W.F, Princípios da filosofia do direito, Traducción de Orlando Vitorino, São Paulo, Martins Fontes, 1997. 
PASOLD, Cesar Luiz. El Taedium Vitae De Norberto Bobbio Y La Ética Médica. Revista Eletrônica Direito e Política, Programa de Pós-Graduação Stricto Sensu em Ciência Jurídica da UNIVALI, Itajaí, v.11, n.1, $1^{0}$ quadrimestre de 2016. Disponível em: www.univali.br/direitoepolitica - ISSN 1980-7791.

HERMANS, Wilhelmus Godefridus, Ética- ensaio sociofilosófico, Brasília, OAB Editora, 2004.

JONAS, Hans, Técnica, medicina y ética- Sobre la práctica del principio de responsabilidade, Traducción de Carlos Fortea Gil, Barcelona, Paidós, 1997. Título original: Technik, Medizin und Ethik. Zur Praxis des Prinzips Veranticortung.

LAFER, Celso, "A MENTIRA- Um capítulo das relações entre a ética e a política". En NOVAES, Adauto (org.), Ética, São Paulo, Companhia das Letras/Secretaria Municipal de Cultura, 1992.

LAFER, Celso, "Um professor: a autobiografia de Bobbio" En CARDIN, Carlos Henrique (org.), Bobbio no Brasil - um retrato intelectual, Brasília, Editora Universidade de Brasília; São Paulo: Imprensa Oficial do Estado, 2001.

LAFER, Celso, "Norberto Bobbio, Teoria do Ordenamento Jurídico", en CARDIN, Carlos Henrique (org.), Bobbio no Brasil - um retrato intelectual, Brasília, Editora Universidade de Brasília; São Paulo, Imprensa Oficial do Estado, 2001.

LAFER, Celso, "Guerra, Direito e poder no Golfo Pérsico" En CARDIN, Carlos Henrique (org.), Bobbio no Brasil - um retrato intelectual, Brasília, Editora Universidade de Brasília; São Paulo, Imprensa Oficial do Estado, 2001.

LAFER, Celso, "Prefácio à Edição Brasileira- A Autoridade de Norberto Bobbio" En BOBBIO, Norberto, 0 tempo da memória. De senectute e outros escritos autobiográficos, Traducción Daniela Versiani, Rio de Janeiro, Campus, 1997. Título original: De senectute.

LIMA, Hermes, Introdução à ciência do direito. $11^{\text {a }}$ edición, Rio de Janeiro, Freitas Bastos, 1961.

MELO, Osvaldo Ferreira de, "Ética e Direito" Em: NEJ. Vol.11, n.1 -p.3539/jan-jun 2006.

MELO, Osvaldo Ferreira de, Dicionário de Política Jurídica, Florianópolis, OAB/SC Editora, 2000.

MENEZES, Daniel, França propõe a sedação terminal para uma morte digna, En http://www.opotiguar.com.br/franca-propoe-a-sedacao-terminalpara-uma-morte-digna/. Acceso el 12 de abril de 2015.

NOVAES, Adauto (org.), Ética, São Paulo, Companhia das Letras/Secretaria Municipal de Cultura, 1992.

PASOLD, Cesar Luiz, Personalidade e Comunicação, $2^{a}$ edición, Florianópolis, Plus Saber Editora, 2005.

PASOLD, Cesar Luiz, O advogado e a advocacia, 3a edición, Florianópolis, OAB/SC Editora, 2001. 
PASOLD, Cesar Luiz. El Taedium Vitae De Norberto Bobbio Y La Ética Médica. Revista Eletrônica Direito e Política, Programa de Pós-Graduação Stricto Sensu em Ciência Jurídica da UNIVALI, Itajaí, v.11, n.1, $1^{0}$ quadrimestre de 2016. Disponível em: www.univali.br/direitoepolitica - ISSN 1980-7791.

PASOLD, Cesar Luiz, Prática da Pesquisa Jurídica e Metodologia da Pesquisa Jurídica, 10ª edición, Florianópolis, OAB/SC Editora, 2007.

PASOLD, Cesar Luiz, Ensaio sobre a Ética de Norberto Bobbio, Florianópolis, Conceito Editorial, 2008.

PASOLD, Cesar Luiz, Metodologia da Pesquisa Jurídica: teoria e prática, 13a edición, Florianópolis, Conceito Editorial, 2015.

PASOLD, Cesar Luiz, O novo Código de Ética Médica: primeira aproximação descritiva, En http://www.advocaciapasold.com.br/publicacoes/artigos.php. Acceso el 8 de abril de 2015.

PASOLD, Cesar Luiz, A Principiologia do novo Código de Ética Médica. En: http://www.advocaciapasold.com.br/publicacoes/artigos.php. Acceso el 8 de abril de 2015.

PENALVA, Luciana Dadalto, As contribuições da Experiência Estrangeira para o debate acerca da Legitimidade do Testamento Vital no Ordenamento Jurídico Brasileiro, En: http://www.advocaciapasold.com.br/artigos/arquivos/testamento_vital_contribuicao.pdf. Acceso el 8 de abril de 2015.

PERELMAN, Chaïm, Ética e Direito, Traducción de Maria Ermantina Galvão G. Pereira, São Paulo, Martins Fontes, 1966. Título original: Éthique et Droit

PESSINI, Leo, Códigos de ética e questões de final de vida: Uma leitura ética comparada, En: http://www.portalmedico.org.br/novocodigo/artigo2.htm. Acceso en 08/04/2015

POLITO, Pietro (org.), "Notas biográficas" En BOBBIO, Norberto, O tempo da memória. De senectute e outros escritos autobiográficos, Traducción Daniela Versiani, Rio de Janeiro, Campus, 1997. Título original: De senectute.

REALE, Miguel, Lições Preliminares de Direito, 10ª edición, São Paulo, Saraiva, 1983.

ROSSI, Pietro, "Introduzione" En ZAGREBESLKY, Gustavo; et ali, Norberto Bobbio tra diritto e política, Roma, Editori Laterza, 2005.

ROUANET, Sérgio Paulo, "Dilemas da Moral Iluminista" En NOVAES, Adauto (org.), Ética, São Paulo, Companhia das Letras/Secretaria Municipal de Cultura, 1992.

SANTILLÁN, José Fernández, "Apresentação- Biografia e história" En BOBBIO, Norberto, (org. José Fernández Santillán), Norberto Bobbio: o filósofo e a política, Traducción de Cesar Benjamin e Vera Ribeiro, Rio de Janeiro, Contraponto, 2003. Título original: Norberto Bobbio: el filosofo y la politica.

SINGER, Peter, Vida Ética- Os melhores ensaios do mais polêmico filósofo da 
PASOLD, Cesar Luiz. El Taedium Vitae De Norberto Bobbio Y La Ética Médica. Revista Eletrônica Direito e Política, Programa de Pós-Graduação Stricto Sensu em Ciência Jurídica da UNIVALI, Itajaí, v.11, n.1, 10 quadrimestre de 2016. Disponível em: www.univali.br/direitoepolitica - ISSN 1980-7791.

atualidade, Traducción de Alice Xavier, Rio de Janeiro, Ediouro, 2002. Título original: Writings on na ethical life.

TUGENDHAT, Ernst, Lições sobre Ética, 3a edición, Traducción de Róbson Ramos dos Reis, et all, Petrópolis, Vozes, 1996. Título original: Vorlesungenüber Ethik.

VIOLI, Carlo (org.), Bibliografia degli scritti di Norberto Bobbio. 19341993, Roma, Gius.Laterza \& Figli, 1995.

VIROLI, Maurizio, "Prefácio", En BOBBIO, Norberto; VIROLI, Maurizio. Diálogo em torno da República: os grandes temas da política e da cidadania, Traducción de Daniela Beccaccia Versiani, Rio de Janeiro: Campus, 2002. Título original: Diálogo intorno alla republica.

WIENER, Norbert, Cibernética e Sociedade. Traducción de José Paulo Paes, 7 a edición, São Paulo, Cultrix, 2000. Título original: The Human use of Human Beings.

Submetido em: janeiro de 2016.

Aprovado em: março de 2016. 